\title{
Regulation of carbohydrates partitioning and metabolism of the common hyacinth
}

\author{
Addai, I. $\mathrm{K}^{1}$ and Scott, $\mathrm{P}^{2}$ \\ ${ }^{1}$ Corresponding author's address: Flat 38F, Park Village, Sussex University, Falmer, \\ Brighton, BN1 9RD (UK) or The Agronomy Department, UDS, P. O. Box 1350, Tamale, \\ Ghana. E-mail: isaackwaheneaddai@yahoo.com; Tel: 00447919610749 \\ ${ }^{2}$ Biology and Environmental Science Department, University of Sussex, Falmer, Brighton, UK
}

\begin{abstract}
The biochemical principles underlining the partitioning and metabolism of starch in most ornamental geophytes are poorly understood. Studies were undertaken at the Biology and Environmental Science Department of the University of Sussex, Falmer, UK with a view to investigating the regulation and partitioning of carbohydrates in flower bulbs using the common hyacinth as test plant. Results indicated that, among the various carbohydrates measured in this geophyte, starch was the major storage carbohydrate, and its degradation occurred through amylolysis rather than phosphorolysis. Starch and biomass contents of the bulb scales decreased whilst those of the newly formed organs increased after planting. Following the depletion of the reserves in the bulb scales, the flower accumulated the highest amount of starch and biomass whilst the stem and roots had the least amount of these quantities. The distribution of enzymes involved in starch degradation in the bulb scales closely followed the pattern exhibited by starch degradation in these organs. Similarly, starch and biomass accumulation of the newly formed organs mimicked the accumulation of these quantities in those organs. ADP glucose pyrophosphorylase and starch synthase were equally responsible for the accumulation of starch in the flower as well as the newly formed leaves, but these enzymes were less responsible for starch accumulation in the stem and roots.
\end{abstract}

Keywords: carbohydrate partitioning, carbohydrate metabolism, the common hyacinth, starch degradation, enzyme activity.

\section{INTRODUCTION}

Hyacinth is an ornamental geophyte belonging to the family Hyacinthaceae and the genus Hyacinthus. The plant is a native of the West and Central Asia. The diploid forms of the plant have 16 chromosomes of 5 different types, but there are also triploids $(3 n=24)$ and a large number of heteroploid (Rees, 1972). The leaf bases and scales of hyacinth are usually fleshy and white, and are swollen with food reserves. Older leaf bases and scales, which have little reserved food, again surround the previous scales and leaf bases. The outermost scales are thin and papery. Hyacinthus orientalis is a spring flowering bulb. Flowers of hyacinth are hermaphroditic, and have a strong sweet fragrance that can fill the air for a considerable distance (Gender, 1994) and are generally pollinated by bees (Davis, 1990). Hyacinth is cultivated mainly for the production of cut flowers, potted plants or as landscaping plants and therefore adds colour to gardens and homes. It therefore occupies a significant position within the world-wide production and trade in cut flowers (VBN
Statistiekboek report, 2002). The plant is also used in the perfumery industries because an essential oil is extracted from its flowers for the manufacture of perfumes. Usher (1974) reported that an amount of $6,000 \mathrm{~kg}$ of the flowers produces $1 \mathrm{~kg}$ of the oil. The plant also produces blue dye.

The most abundant storage components in plants are the carbohydrates. These compounds are the sources of energy for plant growth and development. Carbohydrates also allow plants to synthesize many structural components as well as enhancing the distribution of energy and substrates between different tissues of the plants (Smith, 1999). Starch is the major storage carbohydrate in most ornamental geophytes, and the carbohydrate is nearly ubiquitous throughout the plant kingdom. In plants, starch may exist either as unbranched amylose, with chains of about 1000 glucose residues ( $\alpha-1,4$-linked D-glucose residues), or as amylopectin, a branched polymer with perhaps 25-50 glucose residues between $\alpha-1$, 6 -branch points. Sucrose is the main translocated 
carbohydrate in plants, and its concentration increased during bulb reserve mobilisation and assimilates export. The breakdown and metabolism of sucrose is of paramount importance to flower bulbs because it facilitates the growth of storage organs, inflorescence and other sinks (Miller and Niu, 1990). Flower bulbs contain a number of reserved carbohydrates such as glucose, fructose, sucrose, starch, glucomannans and fructans. While reserve carbohydrates play a vital role during the initial growth of geophytes, little is known about their biochemistry and metabolism (Miller, 1992). The ability of geophytes to store and remobilise reserved metabolites, especially carbohydrates for their own growth and development has revitalised the interest in these plants especially in the area of carbohydrate metabolism. However, information on the biochemistry of regulation of carbohydrate partitioning and metabolism on flower bulbs in general, and hyacinth in particular is very limited. Data on the specific details concerning the degradation and biosynthesis of starch in hyacinth is non existent. Most of the reported literature on this topic was centred on starch degradation by $\alpha$ amylase in the endosperm of germinating seeds, especially in barley or rice which are all members of the Poaceae (Stanley et al., 2005). Zeeman et al. (2004) stated that modelling and studies involving potato (Solanum tuberosum) and Arabidopsis thaliana mutants provided the most recent understanding of starch breakdown in plants. Beck and Ziegler (1989) reported that $\alpha$-amylase and ADPglucose pyrophosphorylase are the two main enzymes that play a major role in the degradation and biosynthesis of plant starch, respectively.

Thomas et al. (1971) reported that starch synthesis in plants is known to be regulated by ADPglucose pyrophosphorylase, the enzyme that catalyzes the synthesis of ADPglucose which is the substrate for starch synthase and starch branching enzyme. Plants also contain a range of starch hydrolytic enzymes such as $\beta$-amylase which is an exoamylase that breaks down $\alpha$-1,4-glucosidic linkages from the nonreducing ends of starch molecules releasing maltose and producing $\beta$-limit dextrin; $\alpha$-amylase an endoamylase responsible for degrading the nonterminal glucosidic linkages to produce glucose, maltose, maltotriose, and branched oligosaccharides; $\alpha$-glucosidase which also breaks down maltose and other oligosaccharides to glucose. Starch phosphorylase also hydrolyses starch leading to the formation of glucose-1-phosphate from starch and inorganic phosphate. In general, the concentration of starch and other carbohydrates in plants differ from species to species and from tissues to tissues, may vary from time to time depending on the stage of growth and the environmental conditions. Thus for example, during the early shoot growth of most geophytes, when stored reserves are utilized, starch content of the storage organs is expected to decrease, and subsequently increase after anthesis, because at this point, carbohydrate filling is rapid (Miller, 1992). Vishnevetsky et al. (2000) reported that, only small changes in starch content were detected during the first month of bulb growth, but an increase in starch level was observed at later stages of development. They observed that the activity of ADP-glucose pyrophosphorylase, a key enzyme of starch synthesis, increased just before the increase in starch accumulation, and sucrose was the dominant soluble sugar in the bulbs whilst only traces of glucose and fructose were detected. Having a good knowledge of carbohydrate content of the various organs of hyacinth at various stages of growth and development of the geophyte, and the distributions of the activity of enzymes related to carbohydrate metabolism in this plant will not only provide a good understanding about the physiology of this plant, but will provide understanding into the biochemistry of carbohydrate metabolism as well as growth and development of the plant. The present study was therefore conducted with a view to investigating the partitioning, regulation and metabolism of carbohydrates particularly starch of the common hyacinth. The study sought to determine the changes in the concentration of glucose, fructose, sucrose and starch during the growth of the bulb, and to determine the relationship between starch and sugars as well as the distribution of activities of hydrolytic and biosynthetic enzymes involved in starch metabolism of this flower bulb.

\section{MATERIALS AND METHODS}

Design and set up of experiments: Three experiments were conducted in this study. In experiment 1, bulbs of average fresh weight $60 \mathrm{~g}$ were planted in plastic pots of capacity $0.01 \mathrm{~m}^{3}$ filled with compost and perlite in a ratio of 2:1 by volume. The units were arranged on greenhouse benches, and treatments replicated 4 times in randomised complete block design (RCBD). Before planting and at $1,2,3,4,5,6$ and 7 months after planting, the plants were carefully uprooted and dissected into seven scales as L1, L2, L3, L4, L5, L6 and L7 where 
L1 refers to the outermost scale and in that order to the very innermost scale (L7). Each of these components was used for starch, glucose, fructose and sucrose measurements using the method described by Morrell and Rees (1986). Total fresh weight of each scale was determined at each stage of growth using electronic weighing balance and dry weights were also measured by oven drying the samples at $80^{\circ} \mathrm{C}$ for 24 hours. Moisture content was calculated as the difference between the fresh and dry weights expressed as a percentage of the fresh weight. At the end of this experiment, scales $L 1-L 4$ were grouped together as outer scales because they exhibited similar metabolic functions and L5-L7 were also grouped together for similar reasons. In experiment 2, 40 hyacinth bulbs of similar fresh weight were planted, and before planting and at 2, 4, $6,8,10,12,14$ and 16 weeks after planting, the bulbs were dissected into outer scales (L1-L4), inner scales (L5-L7 scales), newly formed leaves, stem (basal plate) plus roots and flower for starch measurement. Fresh weights, dry weights and moisture content were determined similarly as in the previous experiment. In experiment 3 , bulbs of similar initial fresh weights as in the case of the previous experiments were planted and dissected into various hyacinth organs for measurements of activities of $\alpha$ amylase, Starch phosphorylase, ADP glucose pyrophosphorylase and soluble starch synthase at 1 , 2, 3, 4, 5 and 6 months after planting. Design and plant arrangements in experiments 2 and 3 remained the same as that of experiment 1.

Measurements of carbohydrates and enzymes activity: In these measurements, assays made use of methods involving reactions that basically converted NAD to NADH. Measurements were made in an ELISA plate reader (Anthos HTLL spectrophotometer that uses Delta Software). Calculations were based on the extinction coefficient of NADH/NAD at $340 \mathrm{~nm}$. In general, a base rate was established prior to starting the reaction. The reaction was left for about 30 min before another set of readings was made. The difference between the readings was directly related to the amount of enzyme used in the conversion of NAD/NADH (Seals, 2003).

Determination of starch content : The procedure of this assay was to digest the samples into glucose units and assay for the glucose. Fresh samples of the various plant parts after dissection were immediately frozen in liquid nitrogen and blended thoroughly Distilled water $(10 \mathrm{ml})$ was added and the mixture was autoclaved for two hours to solubilise the solution. The mixture was digested at $37^{\circ} \mathrm{C}$ for 4 hours using $100 \mu \mathrm{l}$ of $100 \mathrm{mM}$ sodium citrate at $\mathrm{pH}$ 4.8 , added to $15 \mu \mathrm{l}$ and $0.6 \mu \mathrm{l}$ of amyloglucosidase and $\alpha$-amylase, respectively. Then to each $50 \mu l$ of the starch sample from above, $125 \mu \mathrm{l}$ of $100 \mathrm{mM}$ Hepes, $25 \mu \mathrm{l}$ of $40 \mathrm{mM} \mathrm{MgCl} 2 \cdot 6 \mathrm{H}_{2} \mathrm{O}, 25 \mu \mathrm{l}$ of $50 \mathrm{mM}$ ATP, and $25 \mu$ of $2 \mathrm{mM}$ NAD were added. One unit of hexokinase was added prior to recording the base absorbance readings at $340 \mathrm{~nm}$ on a spectrophotometer. Then one unit of glucose-6phosphate dehydrogenase was also added before the second reading was made. Values obtained were entered into a spreadsheet, and the formula according to Morrell and Rees (1986) was used for the calculation of the starch content.

Determination of the soluble sugars: The samples of the various hyacinth organs were boiled in $100 \%$ as well as $50 \%$ ethanol, and then in distilled water for 4 minutes, separately and extracts from these treatments poured into a flask and labelled as first extraction. The procedure was repeated as second and third extractions. The content of each flask was evaporated to dryness using the rota vapour machine. An amount of $1 \mathrm{ml}$ distilled water was pippetted into a flask containing dry samples and shaken with some glass beads for 4-5 minutes. The sample was digested at $37^{\circ} \mathrm{C}$ for four hours using $100 \mu \mathrm{l}$ of $100 \mathrm{mM}$ sodium citrate at $\mathrm{pH} 5.6,8$ units of invertase ( $\beta$-fructosidase) and $100 \mu$ of the sugar sample. Then to each $50 \mu \mathrm{l}$ of the sugar sample from above, $125 \mu$ of $100 \mathrm{mM}$ Hepes, $25 \mu \mathrm{l}$ of $40 \mathrm{mM}$ $\mathrm{MgCl}_{2} \cdot 6 \mathrm{H}_{2} \mathrm{O}, 25 \mu \mathrm{l}$ of $50 \mathrm{mM}$ ATP, and $25 \mu \mathrm{l}$ of $2 \mathrm{mM}$ NAD were added. Then, one unit of hexokinase was added prior to recording the base absorbance readings at $340 \mathrm{~nm}$ on a spectrophotometer, followed by another one unit of glucose-6-phosphate dehydrogenase before taking the second reading. One unit of phosphoglucose isomerase (PGI) was also added for the third reading to be made. As in the case of starch measurement, values obtained were entered into a spreadsheet for the calculation of all the various reducing sugars.

(a) Measurement of $\alpha$-amylase activity: The method used in these measurements was adapted from Adams et al. (1981). Buffer to tissues ratio of 1 : 3 was used. The samples were blended and extracted using an extraction buffer that comprised $0.05 \mathrm{M}$ MES at $\mathrm{pH} 5,0.02 \mathrm{M} \mathrm{MgCl}_{2}$, and $0.02 \mathrm{M}$ $\mathrm{CaCl}_{2}$. The mixture was centrifuged at $30,000 \mathrm{~g}$ for $10 \mathrm{~min}$ and the supernatant was kept on ice the same day for the assay. The reaction mixture contained 0.2 
$\%$ soluble starch, $0.2 \%$ limit dextrin, $0.5 \mathrm{M}$ Citrate buffer at $\mathrm{pH} 6$ and the enzyme extract. The mixture was incubated at $25^{\circ} \mathrm{C}$ for $20 \mathrm{~min}$ and dilute $\mathrm{HCl}$ was added to stop the reaction. An iodine reagent was added before measurement was made on a spectrophotometer at a wavelength of $340 \mathrm{~nm}$.

(b) Determination of starch phosphorylase activity: The method used was modified from that employed by Oluoha and Ugochukwu (1991) and Locy (1998). Plant samples (10 g) were homogenised in $15 \mathrm{ml}$ of the extraction buffer containing chilled 0.5 $\mathrm{M}$ sodium citrate buffer $\mathrm{pH} 6.5,0.4 \mathrm{M}$ insoluble PVP and $1 \mathrm{mM}$ EDTA and the homogenate centrifuged at full speed for 10 mins. The supernatant was $30 \%$ saturated with $\left(\mathrm{NH}_{4}\right)_{2} \mathrm{SO}_{4}$ and allowed to dissolve by stirring continuously for 30 mins whilst the mixture was kept cold by putting it on ice. The mixture was again centrifuged as before, the supernatant was discarded and $500 \mu \mathrm{l}$ of distilled water was added and shaken gently to dissolve the precipitate. This mixture was kept on ice for measurements the same day. An amount of $50 \mu \mathrm{l}$ of $0.2 \%$ soluble starch was added to $50 \mu$ of $10 \mathrm{mM}$ glucose-phosphate in $0.1 \mathrm{M}$ Citrate buffer at $\mathrm{pH} 6.5$ and incubated with $100 \mu \mathrm{l}$ of the enzyme extract at $28^{\circ} \mathrm{C}$ for $10 \mathrm{~min}$. Then $50 \mu \mathrm{l}$ of an iodine reagent was added before measurement was made.

(c) Determination of ADP glucose pyrophosphorylase activity: The method employed in this measurement was adapted from Rochat et al. (1995), Dorion et al. (1996), Pelleschi et al. (1997) and Seal (2003). The plant tissue was blended and the homogenate suspended in $100 \mathrm{mM}$ Tris- $\mathrm{HCl} \mathrm{pH}$ 8 containing $10 \%$ glycerol, $0.1 \%$ ß-mercaptoethanol and $0.1 \%$ bovine serum albumin (BSA). The mixture was centrifuged at $4^{\circ} \mathrm{C}$ at $10,000 \mathrm{~g}$ for $10 \mathrm{~min}$ and the supernatant kept on ice for assay the same day. ADP glucose was assayed in the direction of ADP glucose break down. During measurement, $50 \mu$ of the enzyme extract from above was added to $90 \mathrm{mM}$ Hepes- $\mathrm{HCl}$ at pH 7.4, $3 \mathrm{mM} \mathrm{MgCl} 2,0.6 \mathrm{mM}$ EDTA, $0.8 \mathrm{mM}$ ADP-glucose, $1.1 \mathrm{mM}$ NAD, 0.6 units phosphoglucomutase and 0.5 units glucose- 6 phosphate dehydrogenase. The absorbance at 340 $\mathrm{nm}$ was read as a base reading and $0.7 \mathrm{mM}$ PPi was added to start the reaction for about 30 mins before another reading was made.

(d) Determination of soluble starch synthase activity: In this method, ADP glucose was used to synthesize amylopectin and ADP, and assaying for the ADP produced. It was adapted from Nakamura et al. (1989) and Scott (1992). The same extraction buffer and procedures were used as in the case of ADP glucose pyrophosphorylase. Thus $50 \mu$ of the extract kept on ice from (c) above was added to 50 $\mathrm{mM}$ Hepes-HCl pH 7.4, 0.896 mM ADP glucose, $0.665 \mathrm{mg}$ amylopectin in a total volume of $250 \mu \mathrm{l}$ and incubated in two samples at 25 and $0^{\circ} \mathrm{C}$ for $20 \mathrm{~min}$. The samples were then centrifuged at $12,000 \mathrm{~g}$ for 2 $\min$. Then, $50 \mu \mathrm{l}$ from the incubated samples above was added to $100 \mathrm{mM}$ Hepes at $\mathrm{pH} 7.6,1 \mathrm{mM}$ PEP, $40 \mathrm{mM} \mathrm{MgCl}, 0.2 \mathrm{mM} \mathrm{KCl}, 0.36 \mathrm{mM}$ NAD, 1.5 units lactate dehydrogenase in a total volume of $250 \mu$ l. After $10 \mathrm{~min}$, measurement was made at $340 \mathrm{~nm}$ and 0.4 unit pyruvate kinase was added. The reaction was left at room temperature for one hour before another set of readings was made.

\section{RESULTS}

Partitioning and metabolism of carbohydrates of hyacinth scales : Results from Experiment 1 indicated that fresh and dry weights as well as starch and glucose levels of hyacinth scales decreased from the very outermost scale (L1) to the innermost one (L7) and from planting to five months after planting, but increased from five to seven months after planting (Fig 1a, and 1b; Table 2a) The reduction in starch and dry weight of the scales was greatest during the first month after planting with the outermost scales (L1-L4) recording greater reductions in these parameters as compared to the innermost ones (L5-L7). For instance, the decrease in starch of $\mathrm{L} 1$ was from 306.6 to $211.6 \mu \mathrm{mol} \mathrm{g}^{-1}$ fresh weight, whilst L7 reduced from 214.2 to $170.7 \mu \mathrm{mol} \mathrm{g}$ ${ }^{1}$ fresh weight of starch (Table 2a), representing 31 and $20 \%$, respectively. Reductions in these quantities for L1 were similar to L2, L3 and L4, whilst those of $\mathrm{L} 7$ were also similar to $\mathrm{L} 5$ and L6. Moisture content (Fig 1c) of the scales increased from planting time to four months after planting and decreased from this point to seven months after planting. Fructose and sucrose (Table $2 b$ ) also decreased from planting time to two months after planting, but generally increased from two to five months after planting and almost disappeared at seven months after planting. The disappearance of sugars from the scales as starch accumulated towards the end of the season is further illustrated or shown by the negative correlation between starch and reducing sugars (Table 1: $r=$ $0.094,-0.276,-0.046$ for glucose, fructose and sucrose, respectively). 
Agric. Biol. J. N. Am., 2011, 2(2): 279-297

Table 1: Correlation matrix of biomass and carbohydrates content of hyacinth scales

\begin{tabular}{lccccc} 
& Dry weight & Starch & \multicolumn{1}{c}{ Glucose } & \multicolumn{1}{c}{ Fructose } & Sucrose \\
\hline Fresh weight & 0.869 & 0.669 & 0.562 & -0.244 & 0.519 \\
Dry weight & & 0.694 & 0.611 & -0.155 & 0.327 \\
Starch & & & -0.094 & -0.276 & -0.046 \\
Glucose & & & 0.563 & 0.925 \\
Fructose & & & & 0.52 \\
\hline
\end{tabular}

(a)

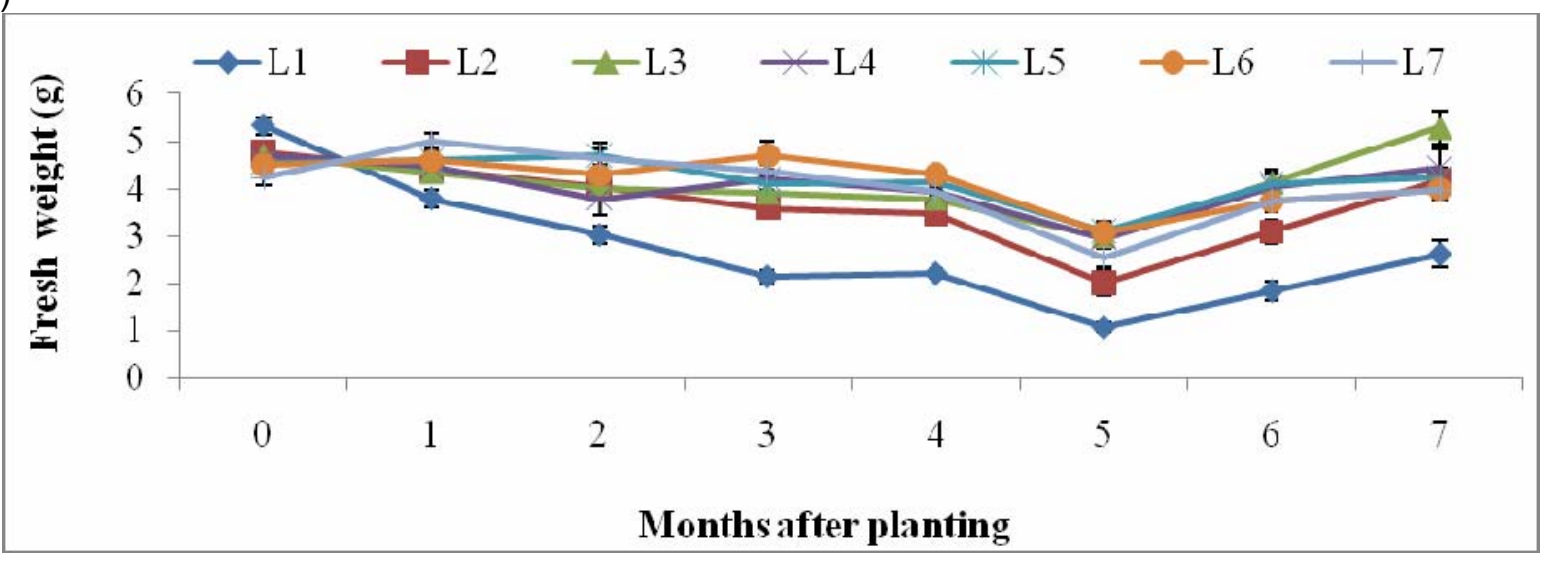

(b)

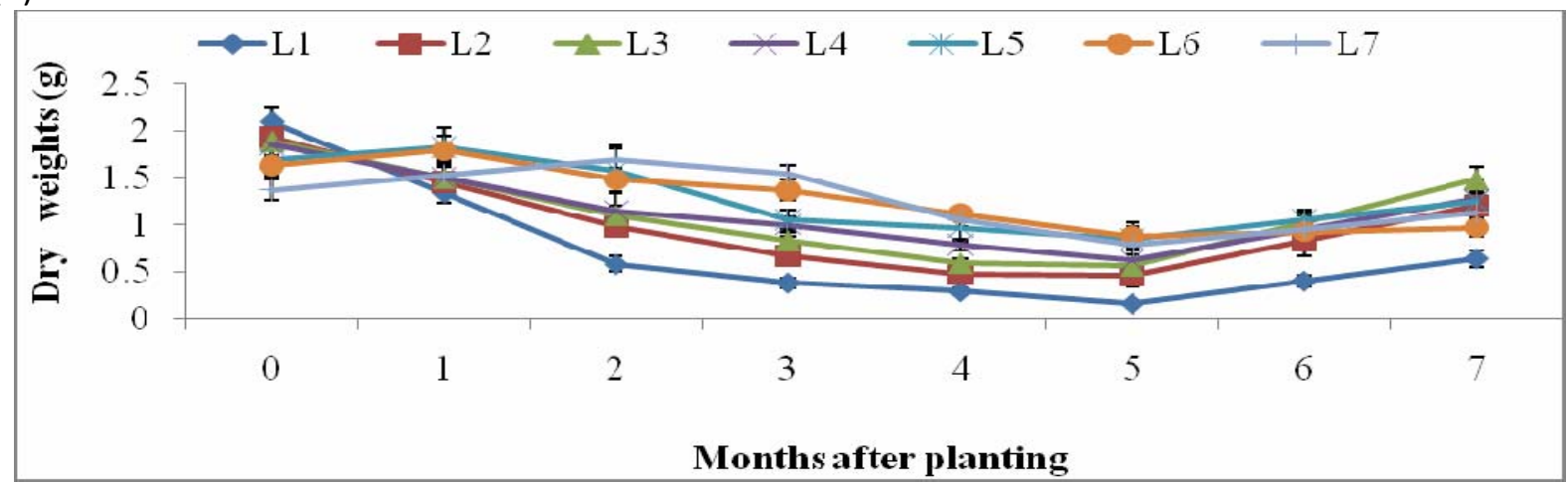

(c)

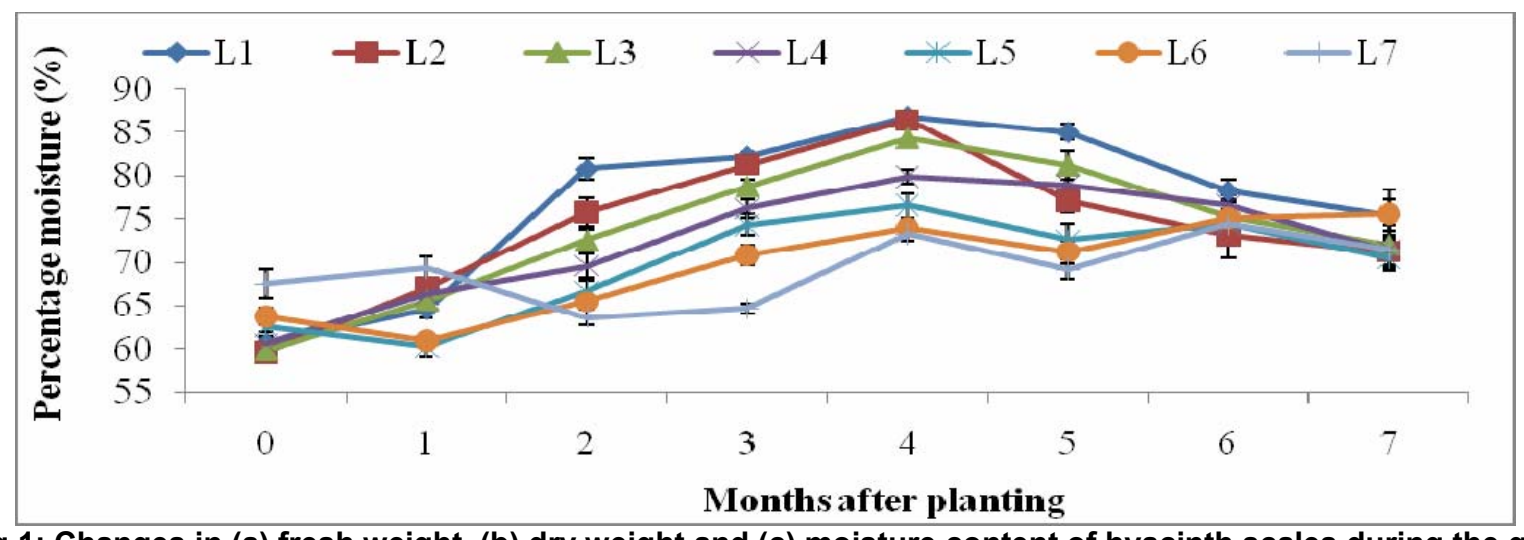

Fig 1: Changes in (a) fresh weight, (b) dry weight and (c) moisture content of hyacinth scales during the growth of the bulb. Bars represent means $\pm S E$ of four replicates. 


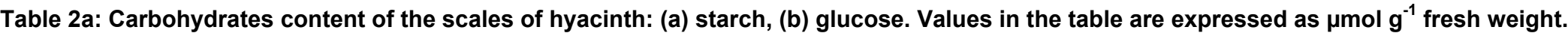

(i) Starch content

\begin{tabular}{ccccccccc} 
& \multicolumn{7}{c}{ Months after planting } \\
\cline { 2 - 8 } Scale leaves & 0 & 1 & 2 & 3 & 4 & 5 & 6 \\
\hline L1 & $306.6 \pm 52$ & $211.6 \pm 34$ & $116.6 \pm 15$ & $71.8 \pm 14$ & $38.5 \pm 4$ & $12.1 \pm 13$ & $109.2 \pm 15$ & $450 \pm 16$ \\
L2 & $284.4 \pm 40$ & $209.5 \pm 27$ & $134.7 \pm 14$ & $94.0 \pm 50$ & $51.6 \pm 9$ & $16.8 \pm 21$ & $148.5 \pm 16$ & $432.1 \pm 12$ \\
L3 & $281.6 \pm 54$ & $204.2 \pm 30$ & $126.7 \pm 60$ & $96.1 \pm 90$ & $53.2 \pm 12$ & $15.9 \pm 26$ & $143.2 \pm 21$ & $377.0 \pm 17$ \\
L4 & $255.6 \pm 35$ & $203.7 \pm 25$ & $151.7 \pm 16$ & $117.4 \pm 16$ & $98.3 \pm 10$ & $32.9 \pm 70$ & $148.5 \pm 11$ & $372.5 \pm 16$ \\
L5 & $249.5 \pm 27$ & $172.6 \pm 24$ & $95.6 \pm 21$ & $122.6 \pm 22$ & $88.5 \pm 10$ & $26.6 \pm 13$ & $126.4 \pm 10$ & $273.6 \pm 70$ \\
L6 & $234.3 \pm 47$ & $171.6 \pm 33$ & $108.9 \pm 18$ & $159.7 \pm 80$ & $86.2 \pm 90$ & $25.9 \pm 30$ & $144.0 \pm 50$ & $273.5 \pm 70$ \\
L7 & $214.2 \pm 26$ & $170.7 \pm 18$ & $127.2 \pm 10$ & $165.9 \pm 13$ & $80.6 \pm 70$ & $23.2 \pm 70$ & $141.6 \pm 70$ & $278.8 \pm 70$ \\
\hline
\end{tabular}

(ii) Glucose content

\begin{tabular}{|c|c|c|c|c|c|c|c|c|}
\hline L1 & $11.8 \pm 1.5$ & $9.4 \pm 1.2$ & $6.9 \pm 0.9$ & $4.9 \pm 1.1$ & $9.9 \pm 2.3$ & $4.0 \pm 0.8$ & $3.4 \pm 1.2$ & $2.8 \pm 1.6$ \\
\hline L2 & $12.6 \pm 1.1$ & $8.9 \pm 0.9$ & $5.2 \pm 0.8$ & $7.3 \pm 2.5$ & $8.1 \pm 2.4$ & $6.3 \pm 0.7$ & $4.6 \pm 1.3$ & $2.9 \pm 1.8$ \\
\hline L3 & $12.5 \pm 1.2$ & $8.7 \pm 0.8$ & $4.9 \pm 0.4$ & $8.3 \pm 1.1$ & $11.3 \pm 3.0$ & $4.7 \pm 0.6$ & $3.6 \pm 1.1$ & $2.5 \pm 1.6$ \\
\hline L4 & $14.3 \pm 1.3$ & $9.7 \pm 1.1$ & $5.2 \pm 0.9$ & $9.9 \pm 0.7$ & $9.5 \pm 1.6$ & $7.1 \pm 0.9$ & $4.0 \pm 0.6$ & $1.0 \pm 0.3$ \\
\hline L5 & $12.3 \pm 1.7$ & $8.6 \pm 1.0$ & $4.9 \pm 0.4$ & $9.5 \pm 0.4$ & $13.5 \pm 2.0$ & $6.0 \pm 0.3$ & $3.2 \pm 0.2$ & $0.4 \pm 0.1$ \\
\hline L6 & $13.4 \pm 1.0$ & $9.7 \pm 0.8$ & $6.1 \pm 0.5$ & $11.5 \pm 1.8$ & $10.8 \pm 1.6$ & $7.0 \pm 0.8$ & $3.6 \pm 0.5$ & $0.2 \pm 0.1$ \\
\hline L7 & $11.8 \pm 1.2$ & $8.6 \pm 1.0$ & $5.4 \pm 0.8$ & $13.5 \pm 1.1$ & $11.7 \pm 1.1$ & $1.9 \pm 1.0$ & $0.9 \pm 0.7$ & $0.1 \pm 0.3$ \\
\hline
\end{tabular}


Table 2b: Carbohydrate content of the scales of hyacinth: (c) fructose, and (d) sucrose. Values are expressed as $\mu \mathrm{mol} \mathrm{g}^{-1}$ fresh weight.

(i) Fructose content

\begin{tabular}{|c|c|c|c|c|c|c|c|c|}
\hline \multicolumn{9}{|c|}{ Months after planting } \\
\hline Scale leaves & 0 & 1 & 2 & 3 & 4 & 5 & 6 & 7 \\
\hline L1 & $4.4 \pm 1.4$ & $2.8 \pm 1.0$ & $1.1 \pm 0.6$ & $4.7 \pm 0.8$ & $2.8 \pm 0.2$ & $4.0 \pm 0.3$ & $2.7 \pm 0.6$ & $1.5 \pm 0.8$ \\
\hline L2 & $4.9 \pm 0.7$ & $2.8 \pm 0.5$ & $0.6 \pm 0.3$ & $1.6 \pm 0.4$ & $3.9 \pm 1.4$ & $1.7 \pm 1.4$ & $1.6 \pm 1.1$ & $1.6 \pm 0.7$ \\
\hline L3 & $2.6 \pm 0.6$ & $1.8 \pm 0.4$ & $0.9 \pm 0.2$ & $2.1 \pm 0.2$ & $4.1 \pm 2.1$ & $0.1 \pm 2.3$ & $0.2 \pm 1.3$ & $0.3 \pm 0.3$ \\
\hline L4 & $3.2 \pm 0.6$ & $1.7 \pm 0.5$ & $0.1 \pm 0.4$ & $1.2 \pm 0.5$ & $5.1 \pm 1.0$ & $3.7 \pm 2.5$ & $1.9 \pm 2.3$ & $0.2 \pm 0.1$ \\
\hline L5 & $4.3 \pm 1.1$ & $2.5 \pm 0.7$ & $0.7 \pm 0.3$ & $1.6 \pm 0.4$ & $3.2 \pm 0.5$ & $2.8 \pm 1.2$ & $1.4 \pm 0.6$ & $0.2 \pm 0.1$ \\
\hline L6 & $0.9 \pm 0.5$ & $0.8 \pm 0.4$ & $0.7 \pm 0.3$ & $0.3 \pm 0.7$ & $4.8 \pm 1.2$ & $4.6 \pm 1.4$ & $2.3 \pm 0.7$ & $0.2 \pm 0.1$ \\
\hline L7 & $0.7 \pm 0.8$ & $0.7 \pm 0.6$ & $0.7 \pm 0.4$ & $0.3 \pm 0.1$ & $4.0 \pm 0.9$ & $2.8 \pm 1.9$ & $1.5 \pm 1.0$ & $0.3 \pm 0.1$ \\
\hline
\end{tabular}

(ii) Sucrose content

\begin{tabular}{|c|c|c|c|c|c|c|c|c|}
\hline L1 & $16.3 \pm 2.1$ & $12.1 \pm 1.6$ & $8.0 \pm 1.1$ & $9.6 \pm 1.6$ & $12.7 \pm 2.4$ & $8.0 \pm 0.6$ & $6.2 \pm 1.2$ & $4.3 \pm 1.8$ \\
\hline L2 & $17.4 \pm 1.0$ & $11.7 \pm 0.9$ & $5.9 \pm 0.8$ & $8.9 \pm 2.2$ & $11.9 \pm 3.8$ & $4.7 \pm 2.1$ & $4.6 \pm 2.2$ & $4.5 \pm 2.3$ \\
\hline L3 & $15.1 \pm 1.6$ & $10.5 \pm 1.0$ & $5.8 \pm 0.4$ & $10.3 \pm 1.2$ & $15.4 \pm 4.9$ & $4.6 \pm 1.7$ & $3.3 \pm 1.8$ & $2.0 \pm 1.9$ \\
\hline L4 & $17.5 \pm 1.7$ & $11.8 \pm 1.4$ & $6.0 \pm 1.1$ & $11.0 \pm 0.5$ & $14.6 \pm 2.1$ & $3.4 \pm 3.6$ & $2.1 \pm 2.0$ & $0.9 \pm 0.4$ \\
\hline L5 & $14.6 \pm 2.4$ & $10.1 \pm 1.5$ & $5.6 \pm 0.5$ & $11.1 \pm 0.7$ & $16.7 \pm 1.6$ & $3.2 \pm 1.0$ & $1.8 \pm 0.5$ & $0.4 \pm 0.1$ \\
\hline L6 & $14.1 \pm 0.7$ & $10.4 \pm 0.5$ & $6.7 \pm 0.3$ & $11.3 \pm 1.7$ & $15.6 \pm 1.0$ & $2.5 \pm 0.7$ & $1.3 \pm 0.4$ & $0.1 \pm 0.1$ \\
\hline L7 & $12.5 \pm 1.1$ & $9.3 \pm 1.0$ & $6.0 \pm 0.9$ & $13.8 \pm 1.0$ & $15.7 \pm 1.0$ & $4.6 \pm 2.3$ & $2.4 \pm 0.1$ & $0.2 \pm 0.2$ \\
\hline
\end{tabular}


Partitioning and metabolism of starch of the various organs of hyacinth: Carbohydrate studies of the scales of hyacinth revealed that starch was the major storage carbohydrate in the bulb. This is because values of starch measured were very high as compared to the low amounts of the sugars measured of the scales especially prior to planting of the bulbs. Also, there was accumulation of starch in the scales towards the end of the growing season whilst the sugars almost disappeared from these organs. The study thus investigated the partitioning and metabolism of starch as already mentioned in experiment 2. Results showed that biomass and starch content of the scales mimicked those of the previous experiment. Fresh and dry weights as well as starch of the scales were higher in outermost scales than the innermost ones prior to planting (Fig 2). These parameters also decreased from planting to sixteen weeks after planting with the outer scales recording higher reductions in these parameters than the inner ones particularly from 0 to 4 weeks (one month). The total starch content of the outer scales decreased from 7713.15 to $4820.17 \mu \mathrm{mol}$ (Fig 3), whilst the inner scales reduced in starch from 5580.11 to $4628.11 \mu \mathrm{mol}$ at two weeks after planting, and these represent reductions of 38 and $17 \%$, respectively. However, the newly formed organs: stem and roots, new leaves, and flowers showed an increasing trend in these quantities. Moisture content of the organs generally increased from planting to 16 weeks after planting (Fig 3).

Starch metabolism and distribution of enzymes activity of the hyacinth bulb : Measurements of activity of some enzymes that play a major role in starch biosynthesis and degradation of hyacinth were made as part of this study (Experiment 3 ). Results indicated that the distribution of both a-amylase and starch phosphorylase enzymes were significantly different in the hyacinth scales, with the outer scales having higher activity than the inner scales. The activity of these enzymes increased from the inside of the bulb to the outermost scales (Fig 4). Alpha amylase activity increased from planting to November (3 months after planting) coinciding with the period that starch degradation was at its peak in hyacinth (experiment 2 and 3), and then decreased from December to March. However, the enzyme activity remains the same from December to January. Starch phosphorylase activity (Fig 4b) rather increased from September to October (one month after planting) and decreased thereafter to March. ADP glucose pyrophosphorylase activity (Fig 5) generally decreased from September to January and rose to March whilst the activity of the same enzyme in the flower, new leaves and stem generally increased from planting (September) to January (four months after planting), mimicking the distribution depicted by starch content of these organs. The distribution exhibted by starch synthase was similar to that of ADP glucose pyrophosphorylase.

Relationship between starch degradation and enzyme activity: The correlation studies revealed that $\alpha$-amylase better related with starch degradation especially in the outer scales than did starch phosphorylase because the former correlated more positively (Fig 6) with starch degradation in the scales of the bulb than did the latter (Fig 7). Both ADP glucose pyrophosphorylase and starch synthase correlated better with starch accumulation of the flower and the newly formed leaves than they did with the stem and roots (Fig 8 and 9). 
(a)

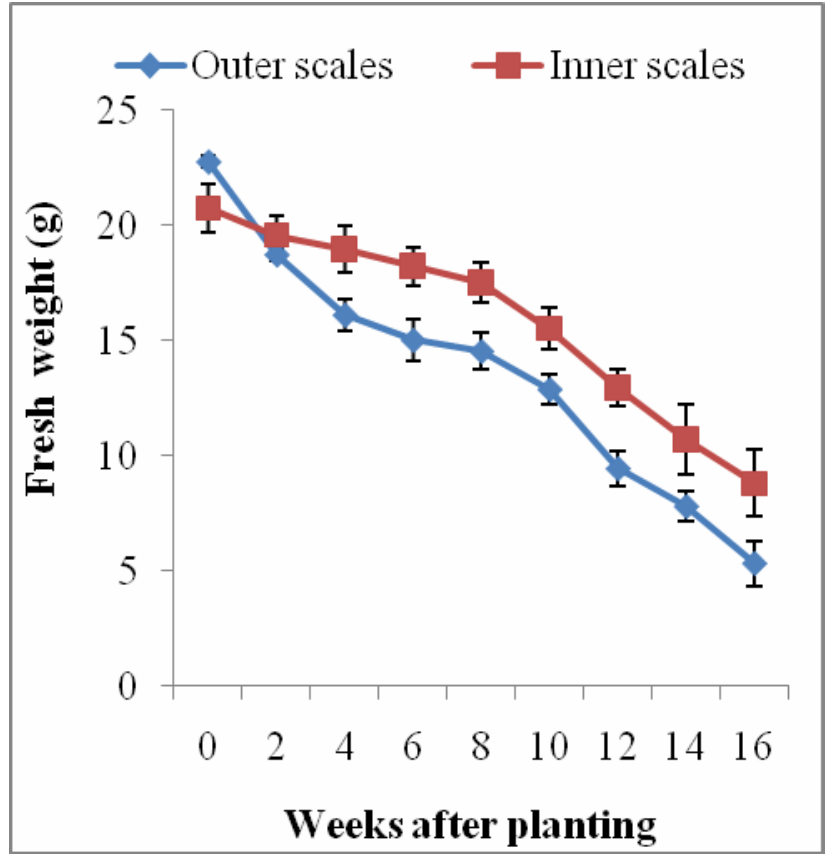

(c)

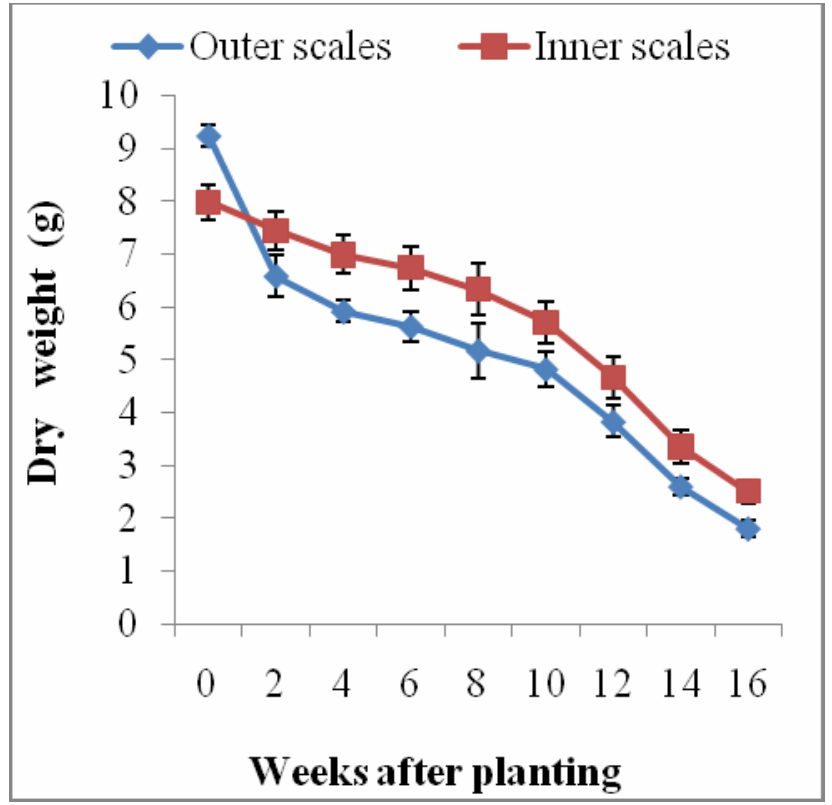

(b)

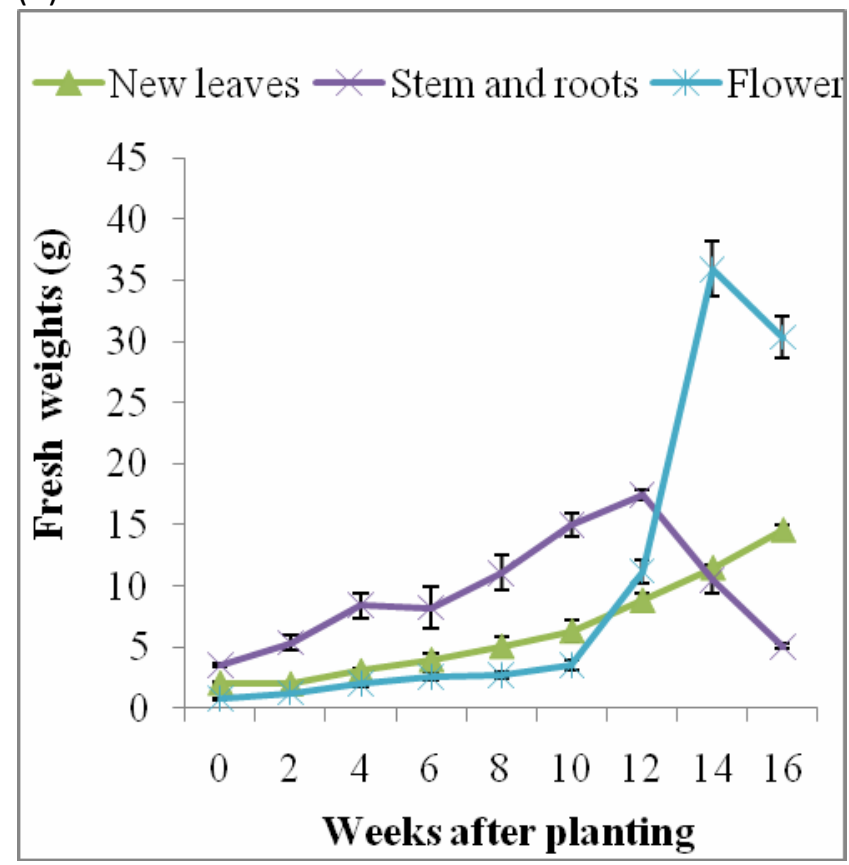

(d)

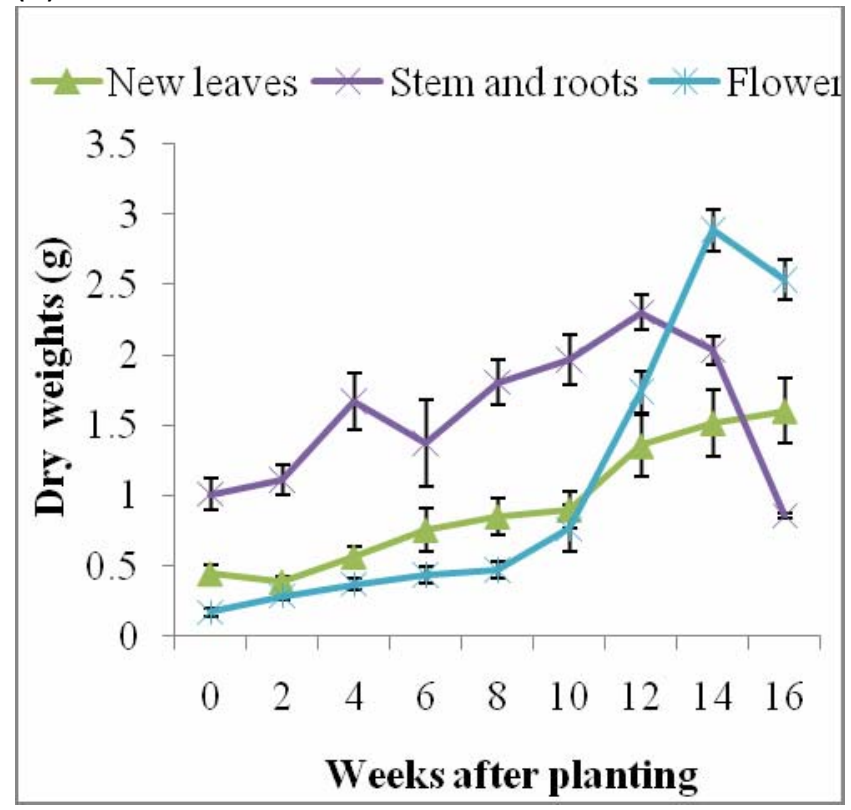

Fig 2: Variation in biomass of hyacinth organs; fresh weight of outer scales (a), fresh weight of the newly formed leaves, stem and roots and flower (b), dry weight of the outer and inner scales (c) and dry weight of the new leaves, stem and roots, and the flower (d). Bars represent means \pm SE of five replicates. 
(a)

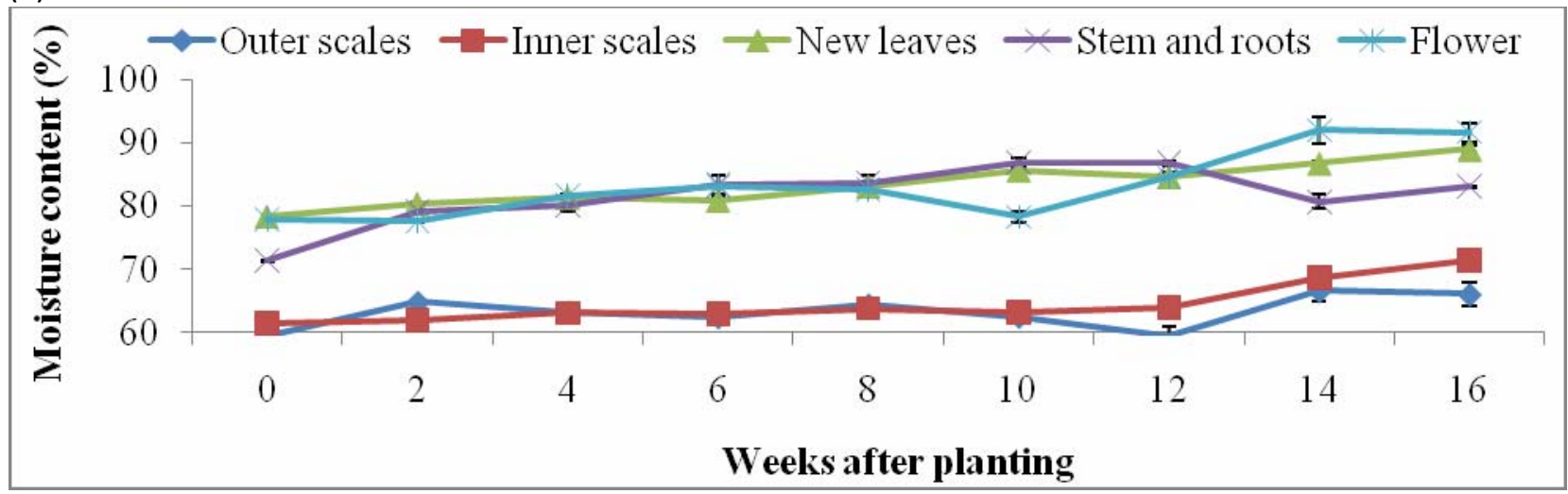

(b)

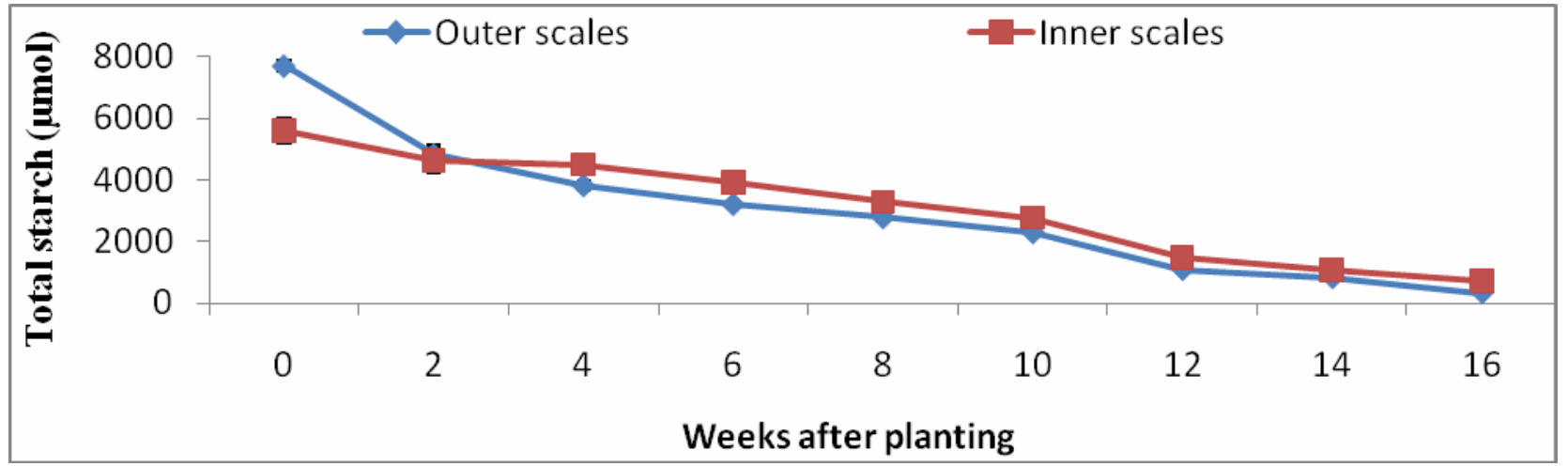

(c)

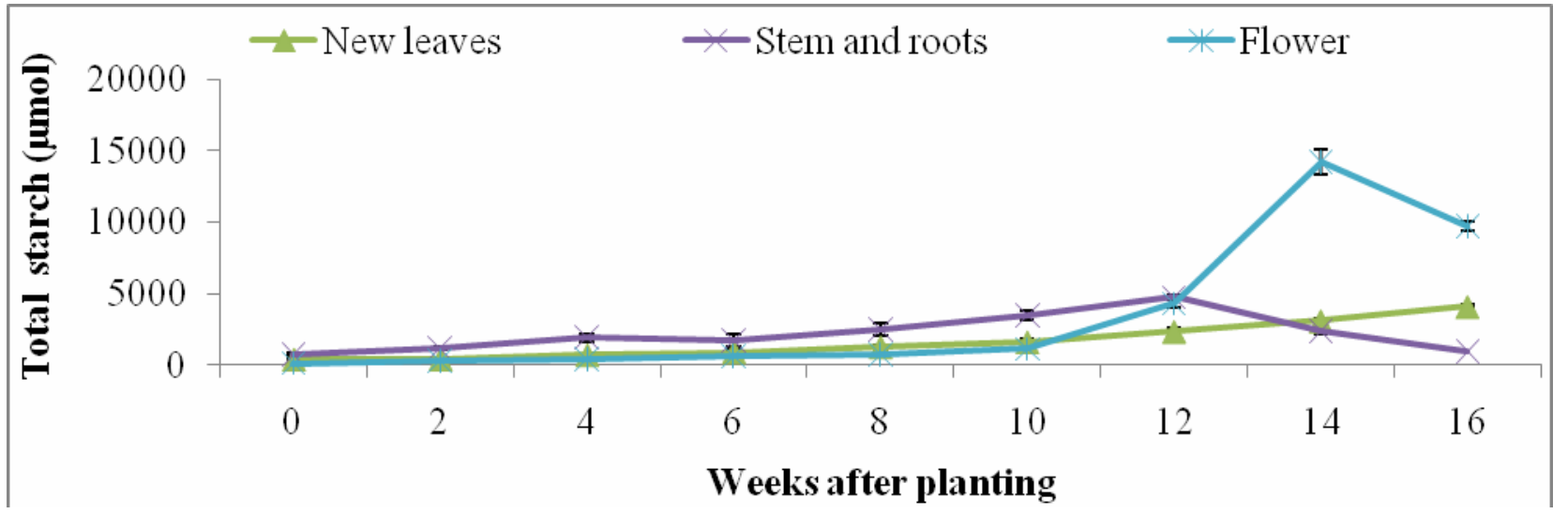

Fig 3: Changes in moisture and starch content of hyacinth bulb organs. The figure indicates the variation in moisture content of the organs (a), total starch content of the outer and inner scales (b) and total starch concentration of the new leaves, stem and roots, and the flower (c). Bars represent means $\pm S E$ of five replicates. 
(a)

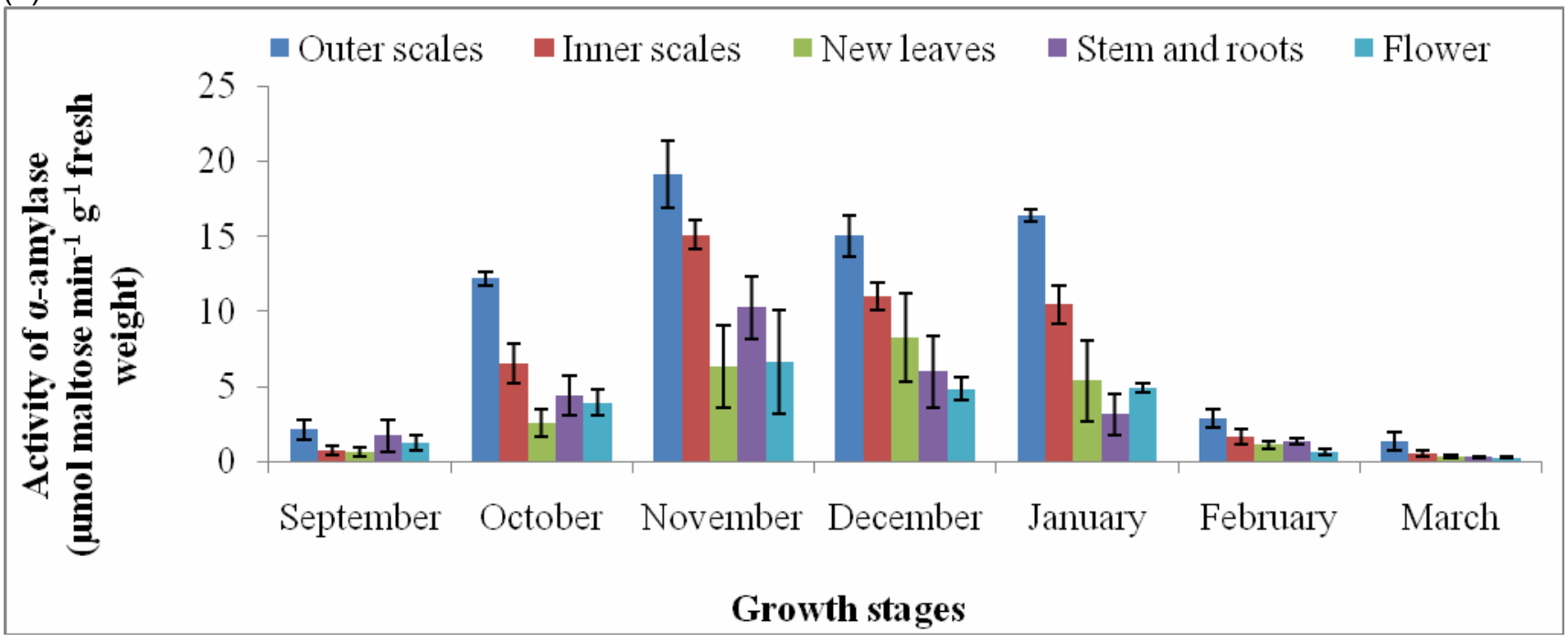

(b)

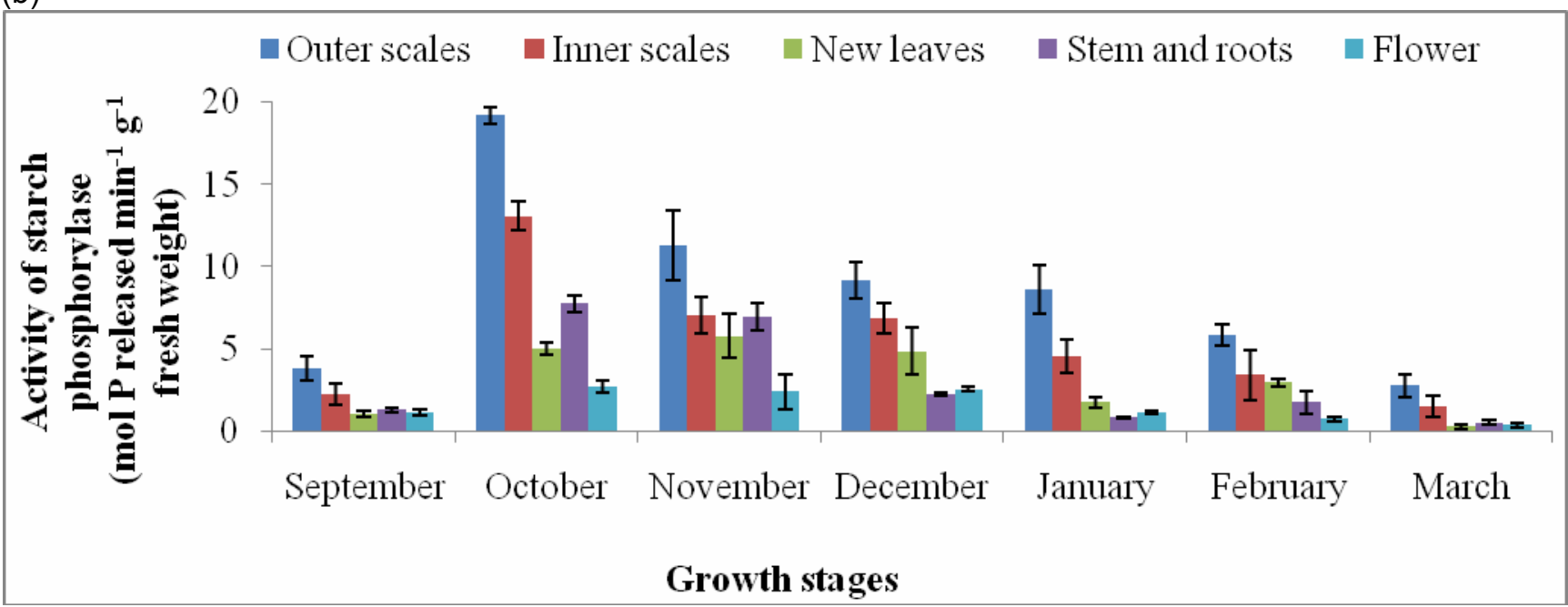

Fig 4: Variation in the activity of starch degrading enzymes during hyacinth bulb production in the 2009/2010 season: (a) $\alpha$ - amylase and (b) starch phosphorylase. Bars represent means $\pm S E$ of five replicates. 
(a)

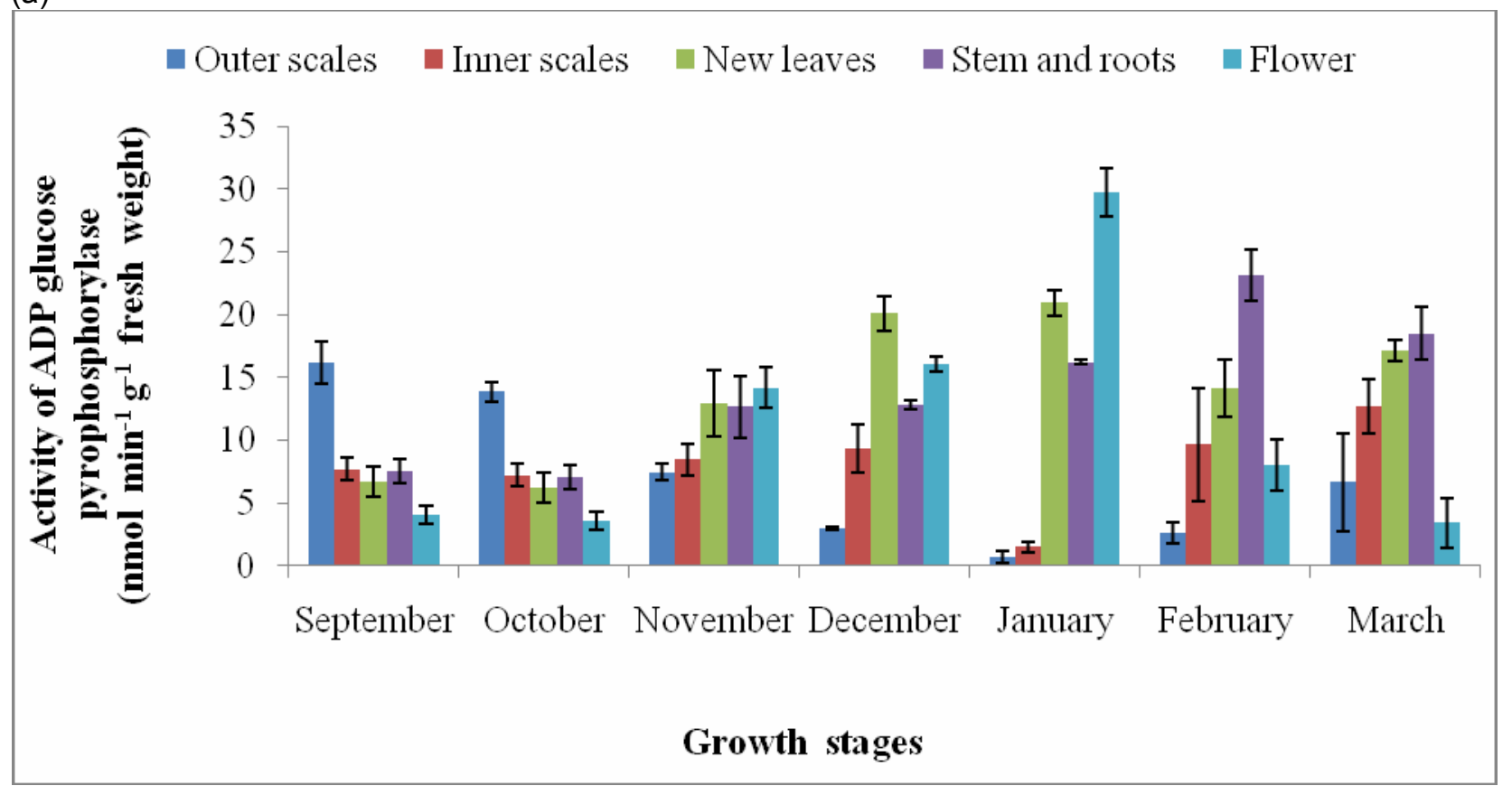

(b)

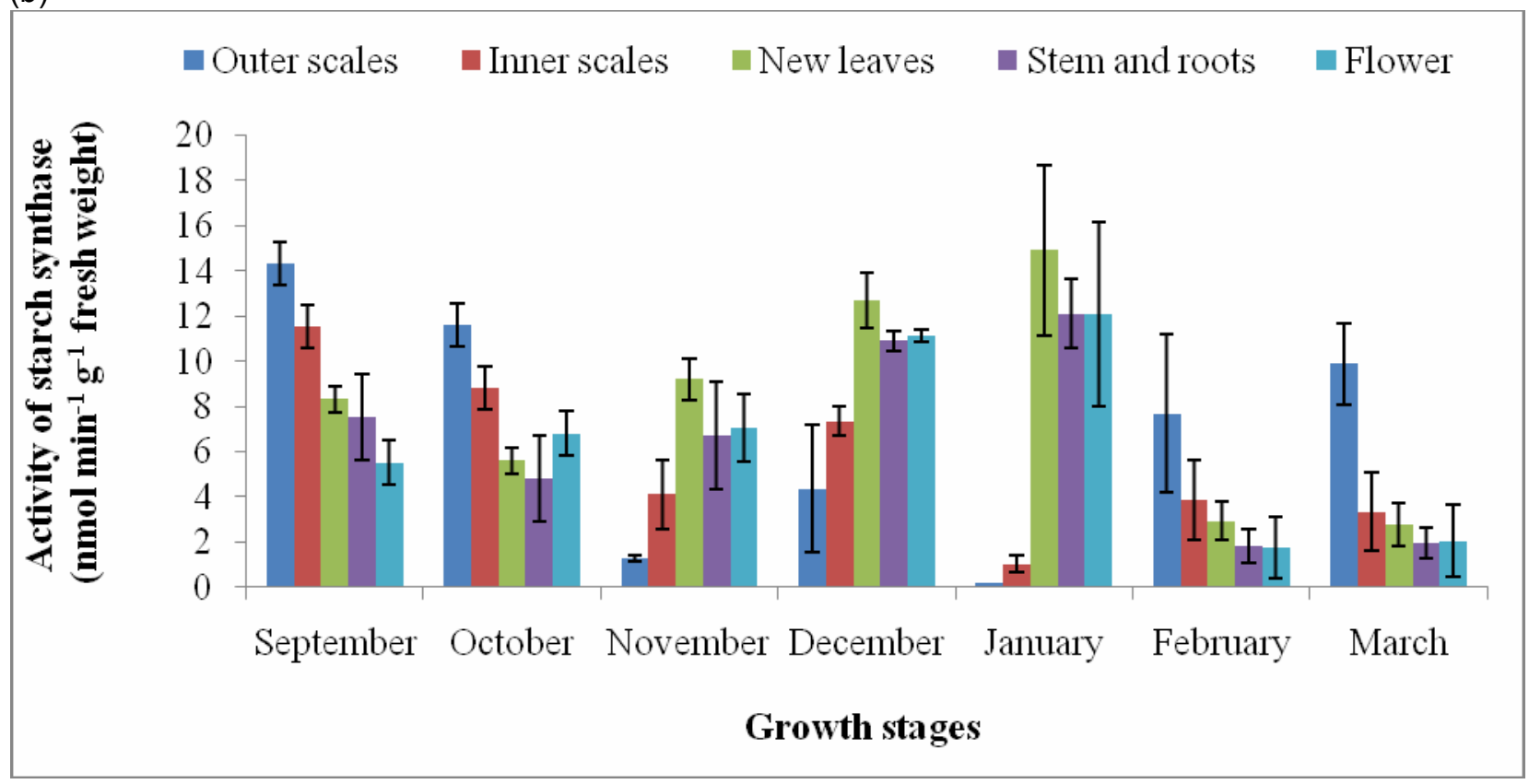

Fig 5: Distribution of activity of starch synthesizing enzymes during the growth of the common hyacinth in 2009/2010 planting season: (a) ADP glucose pyrophosphorylase and (b) starch synthase. Bars represent means \pm SE of five replicates. 
(a)

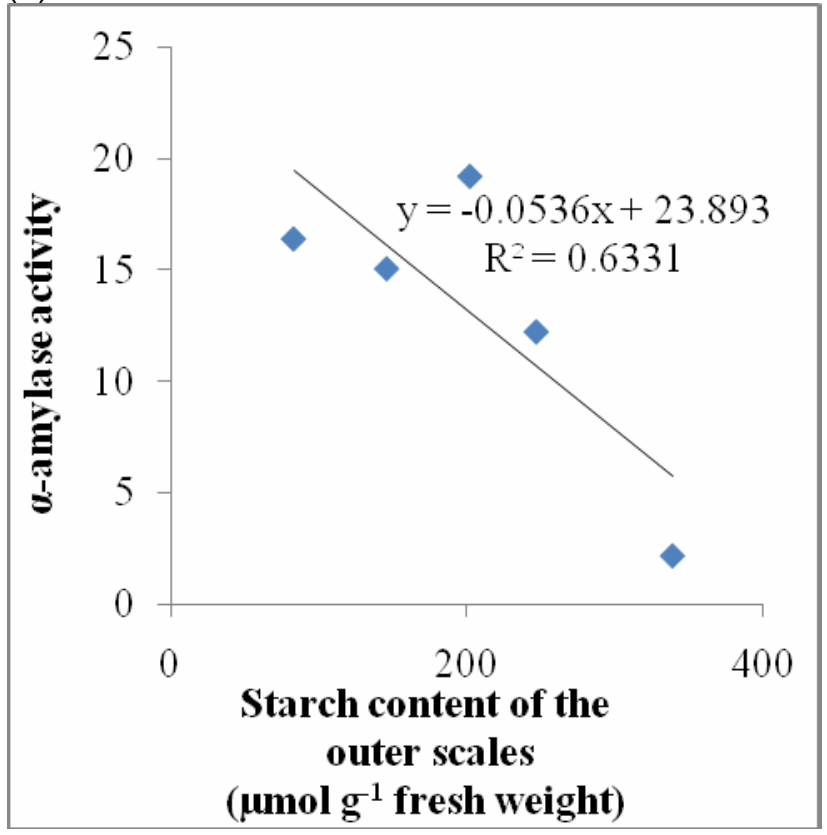

(b)

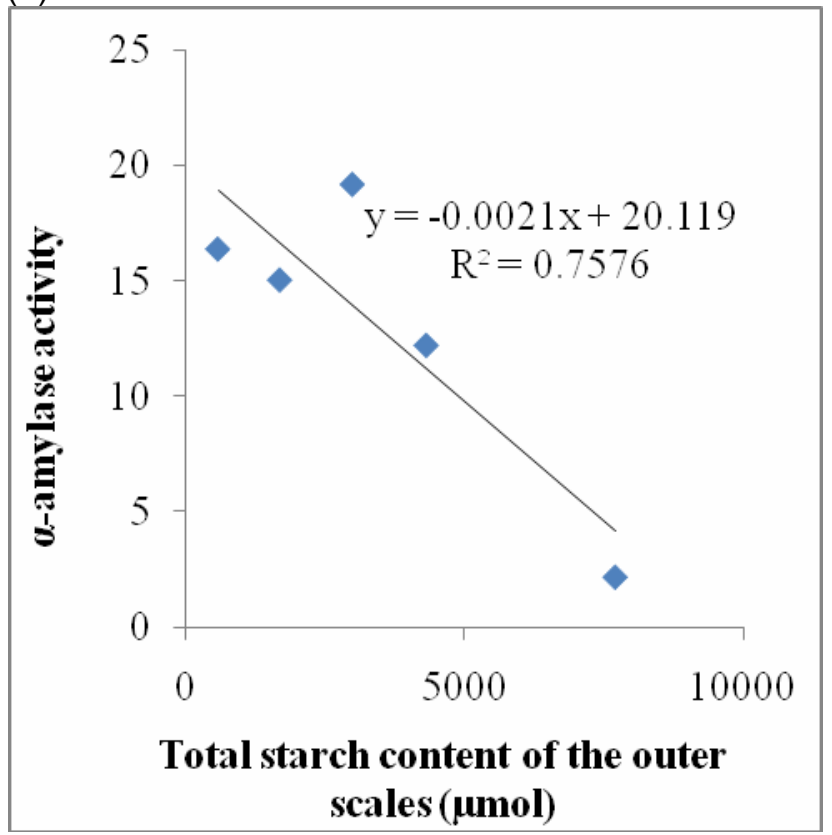

(c)

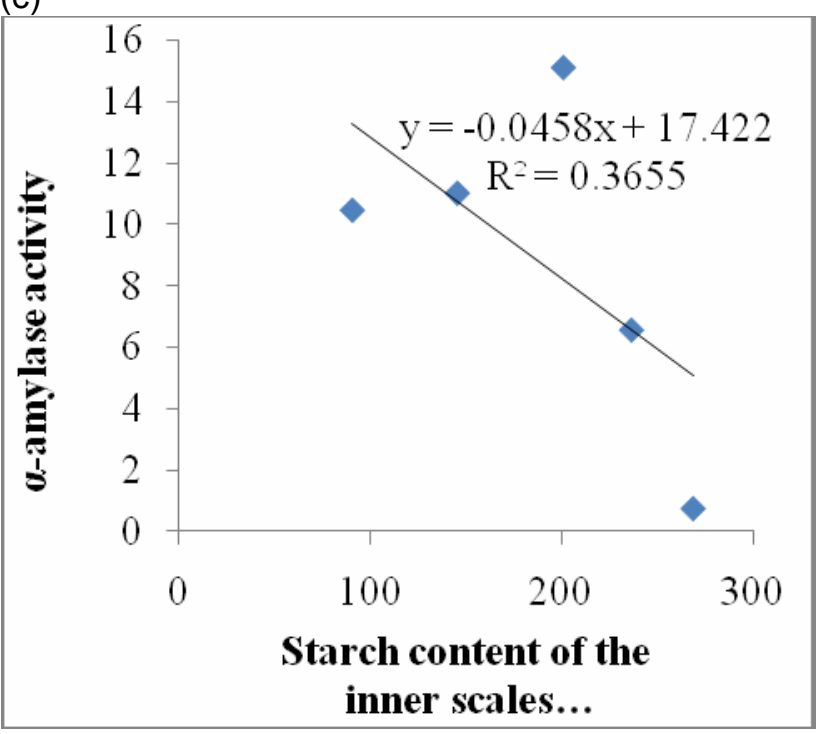

(d)

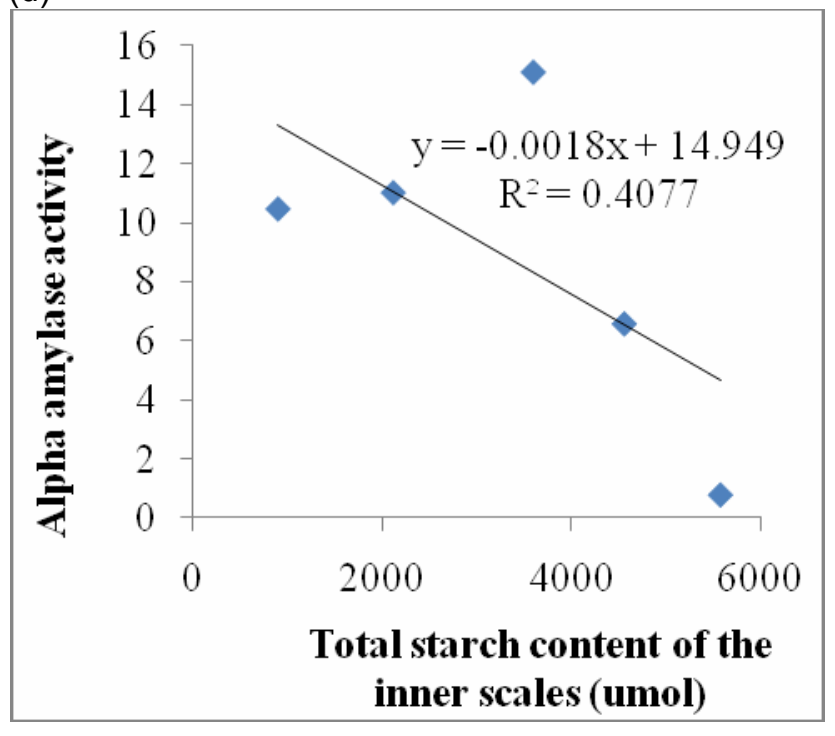

Fig 6: Relationship between $\alpha$-amylase activity and starch degradation of the outer and inner scales of hyacinth. This figure demonstrates the correlation between the activity of $\alpha$-amylase (expressed as $\mu \mathrm{mol}$ maltose $\mathrm{min}^{-1} \mathrm{~g}^{-1}$ fresh weight), and (a) outer scales starch content expressed as $\mu \mathrm{mol}^{-1}$ fresh weight, (b) outer scales total starch content expressed as $\mu \mathrm{mol}$, (c) inner scales starch content expressed as $\mu \mathrm{mol} \mathrm{g}^{-1}$ fresh weight, and (d) inner scales total starch content expressed as $\mu \mathrm{mol}$. The negative slope indicates that as the activity of the enzyme increases, starch degradation increases and hence the concentration of the carbohydrate decreases with time. 
Agric. Biol. J. N. Am., 2011, 2(2): 279-297

(a)

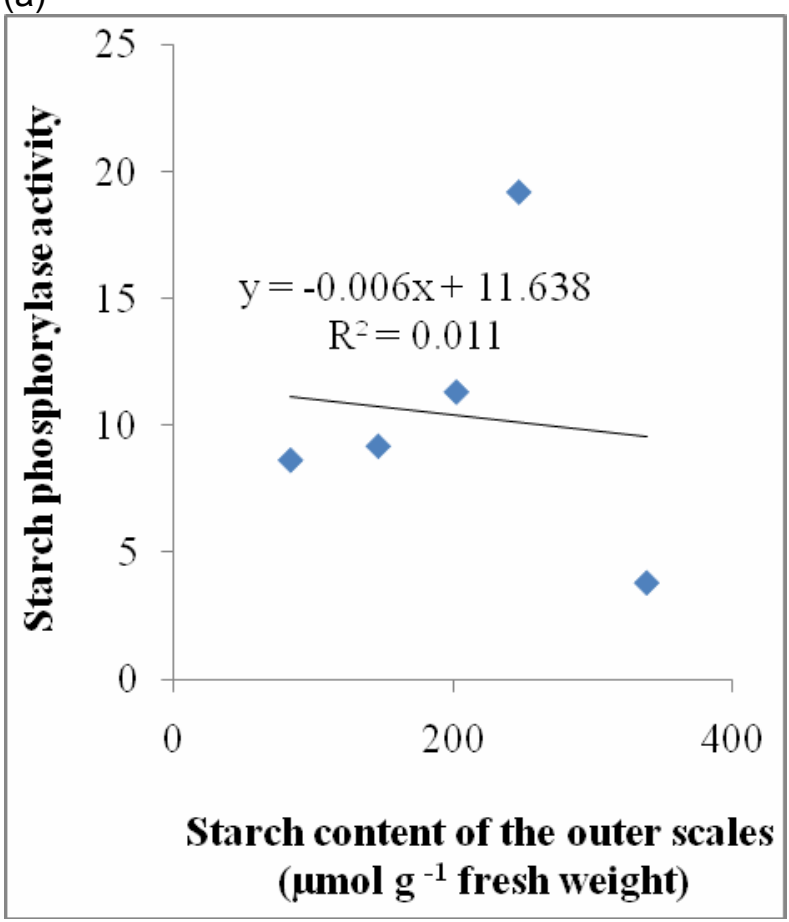

(c)

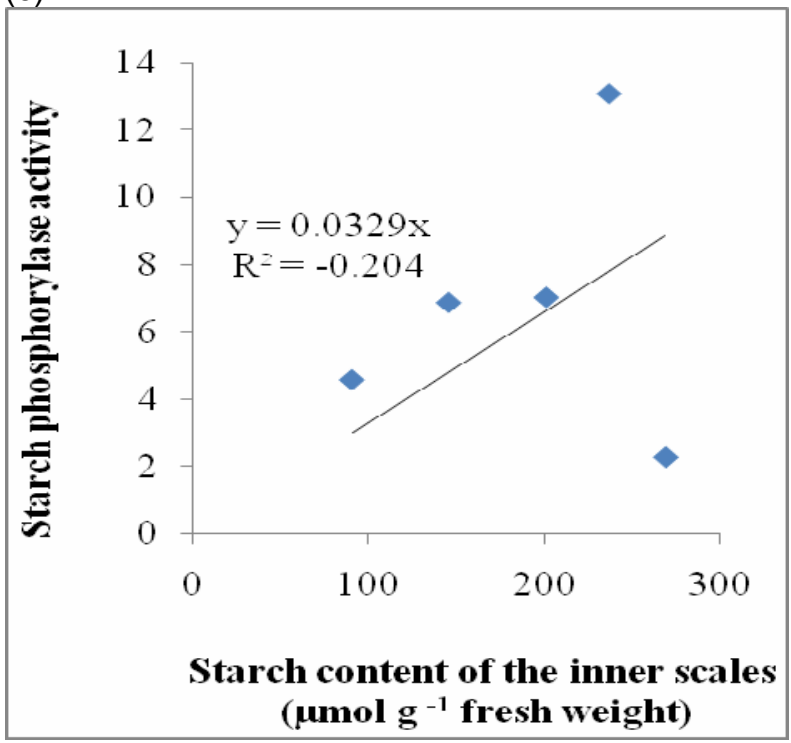

(b)

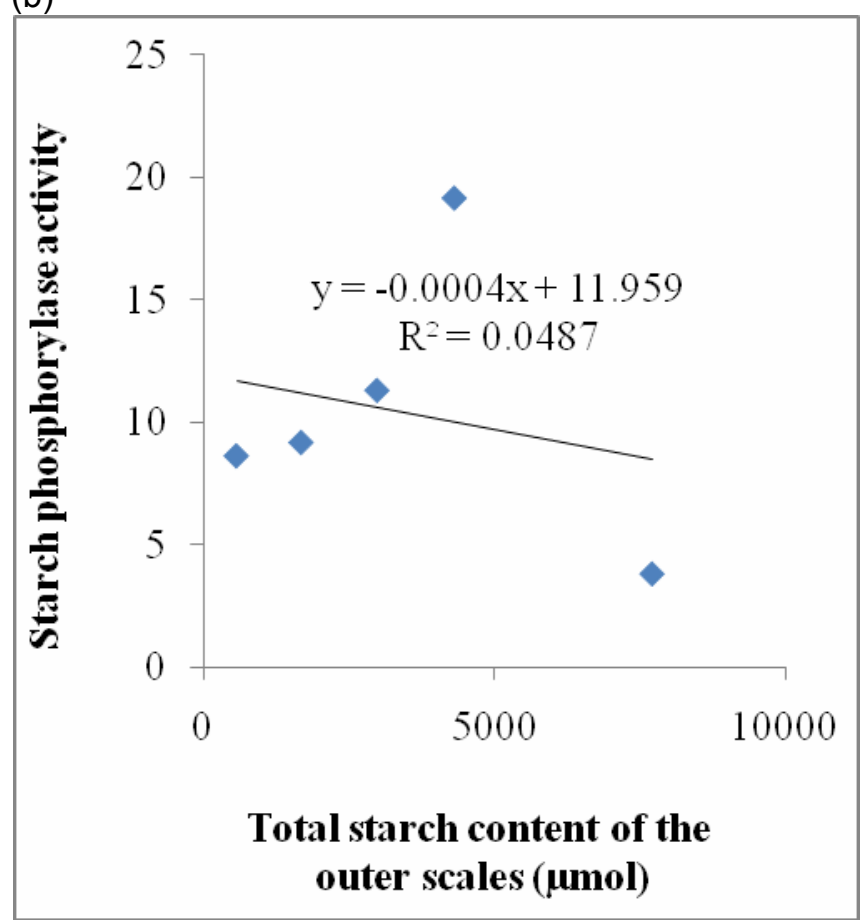

(d)

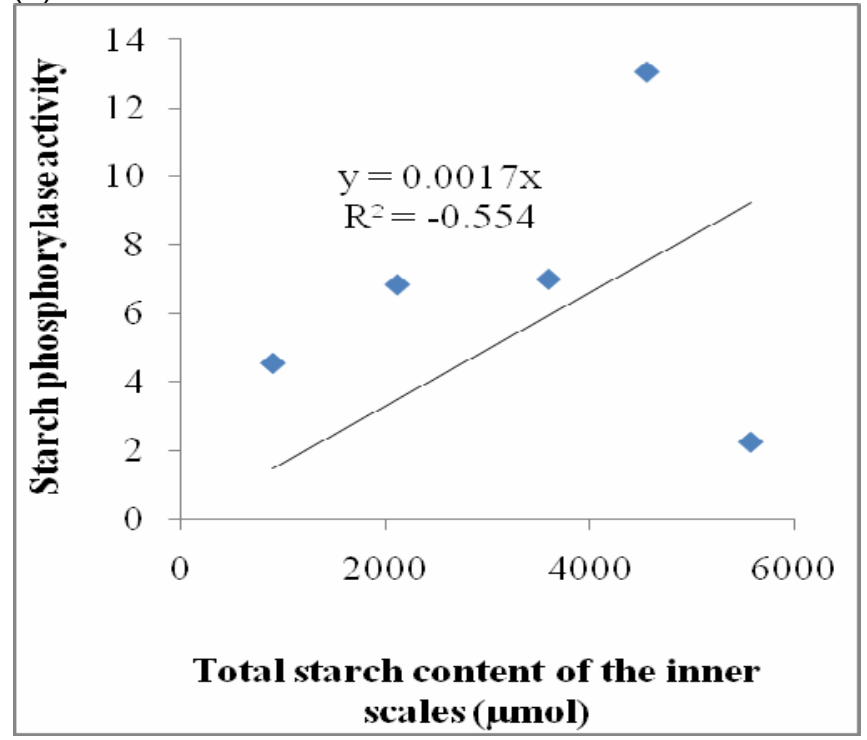

Fig 7: Relationship between starch phosphorylase activity and starch degradation of outer and inner scales of hyacinth. The figure shows the correlation between the activity of starch phosphorylase (expressed as mol P released $\mathrm{min}^{-1} \mathrm{~g}^{-1}$ fresh weight), and (a) outer scales starch content expressed as $\mu \mathrm{mol} \mathrm{g}^{-1}$ fresh weight, (b) outer scales total starch content expressed as $\mu \mathrm{mol}$, (c) inner scales starch content expressed as $\mu \mathrm{mol} \mathrm{g}^{-1}$ fresh weight, and (d) inner scales total starch content expressed as $\mu \mathrm{mol}$. The negative gradients of (a) and (b) as well as the negative correlation of (c) and (d) imply that as the activity of the enzyme increases, starch concentration of the organ decreases with time. 
(a)

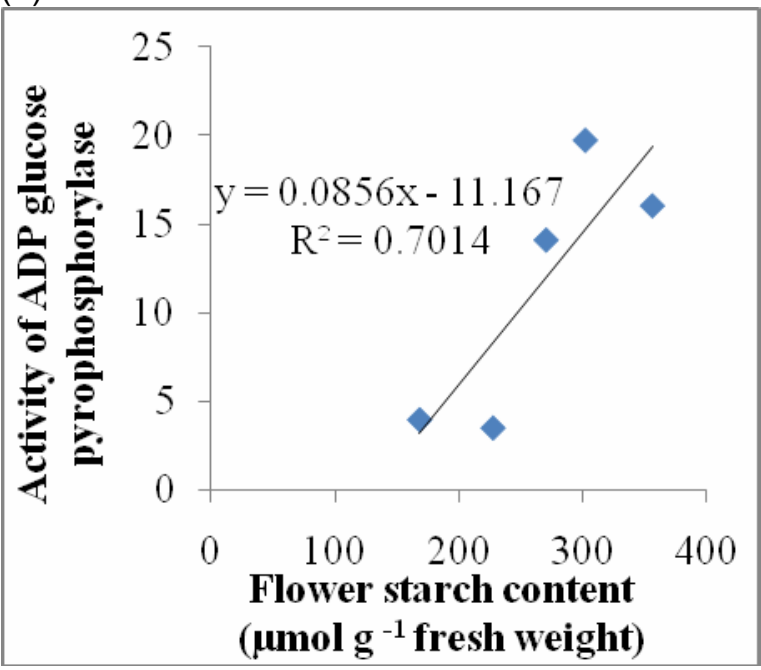

(c)

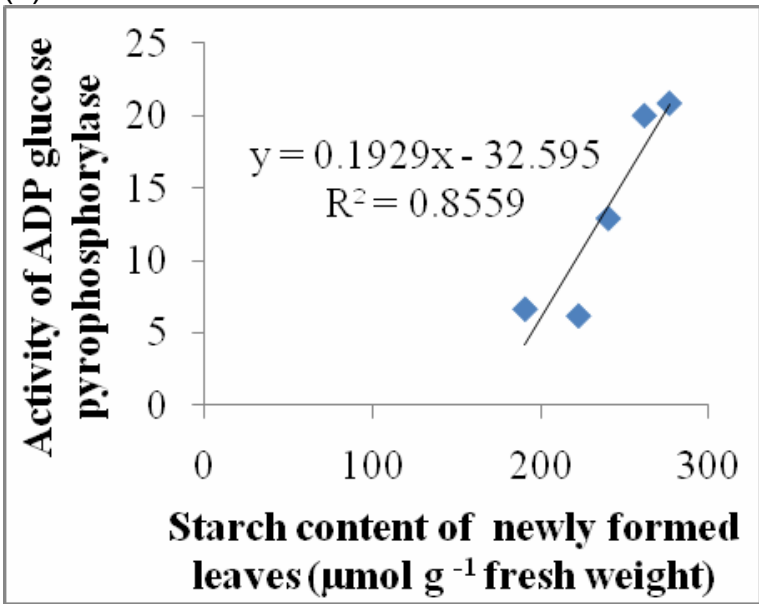

(e)

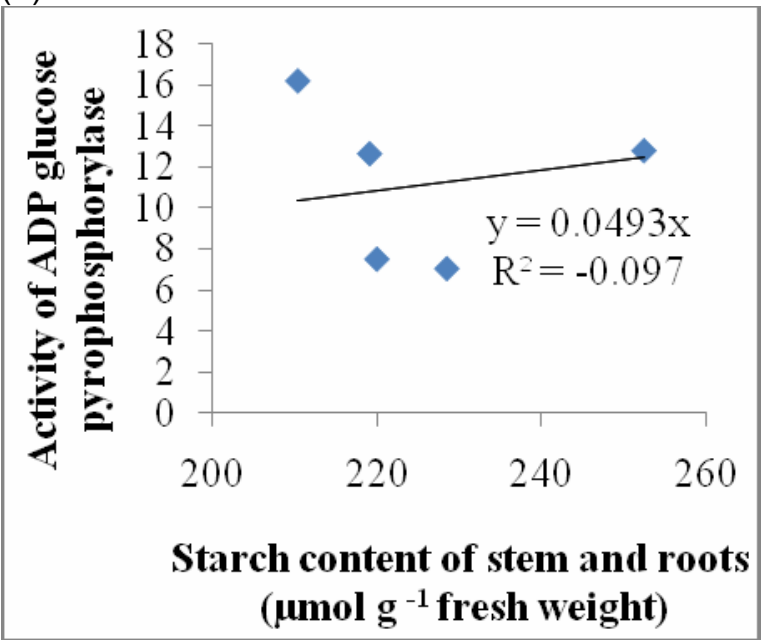

(b)

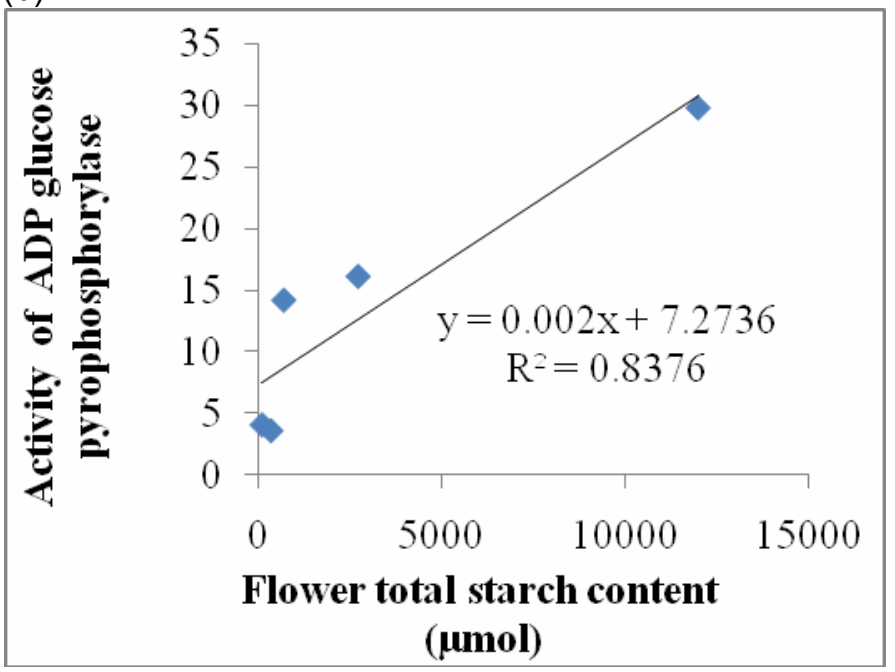

(d)

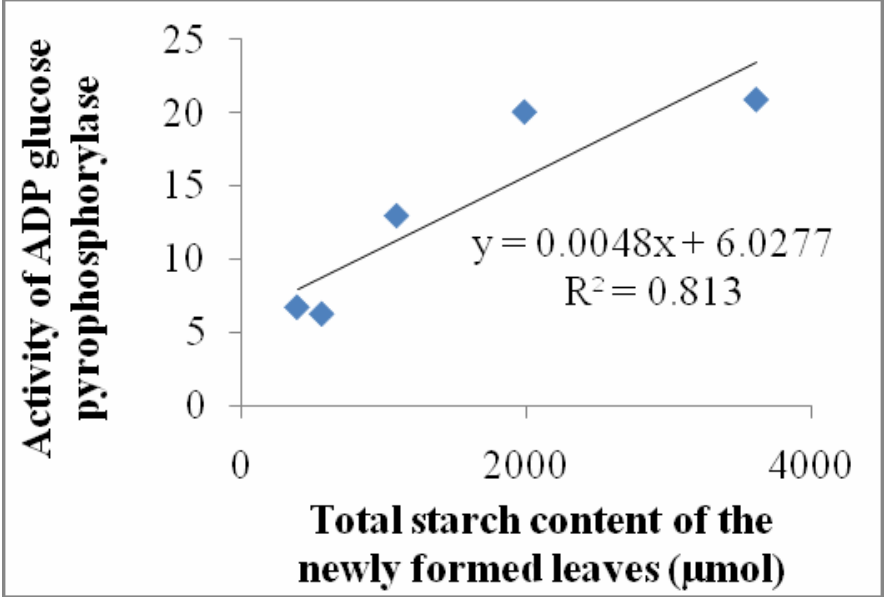

(f)

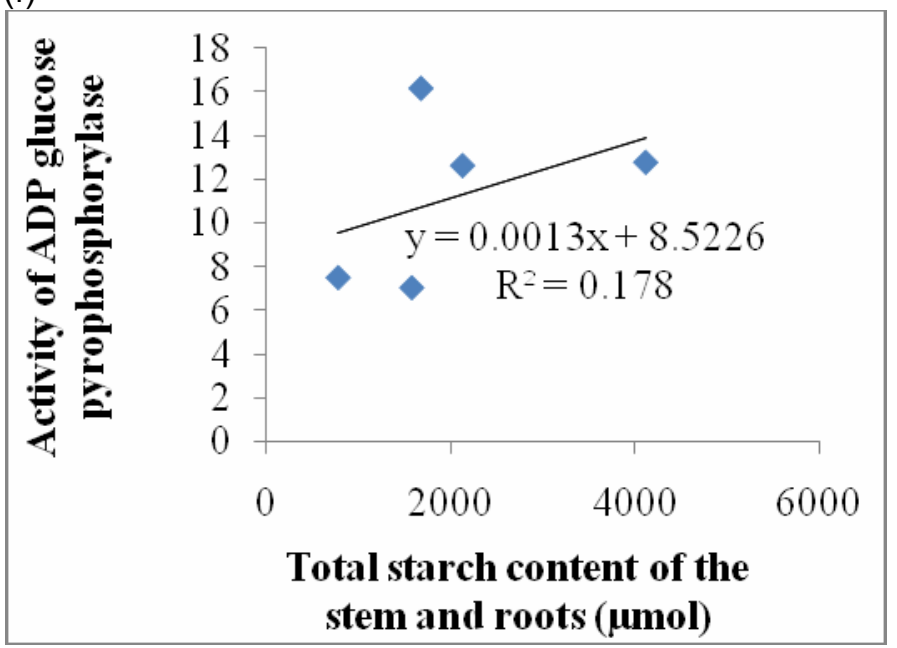

Fig 8: Relationship between the activity of ADP glucose pyrophosphorylase (expressed as nmol $\mathrm{min}^{-1} \mathrm{~g}^{-1}$ fresh weight), and starch accumulation of the flower (a,b), new leaves (c, d) and the stem and roots (e, f) of hyacinth. The positive slopes of the graphs suggest that the activity of this enzyme varies directly with starch accumulation. 
(a)

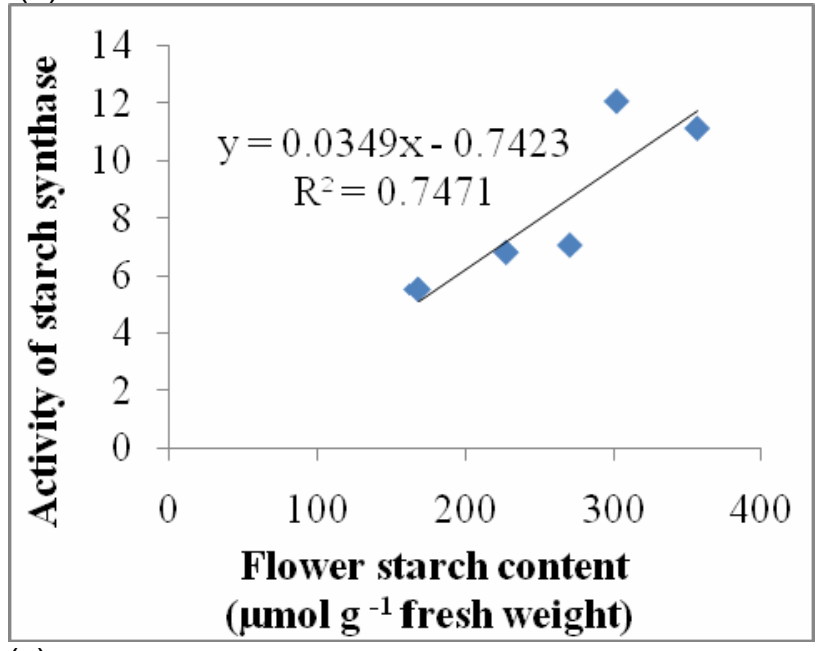

(c)

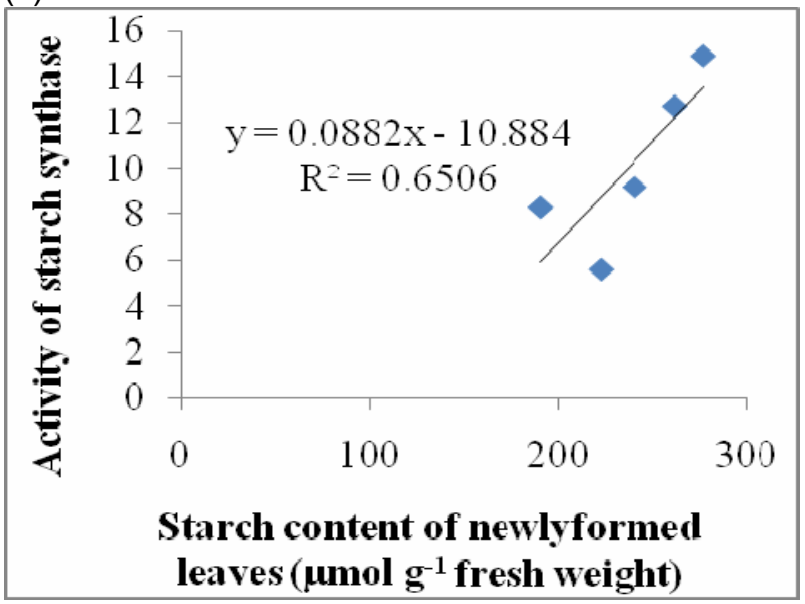

(e)

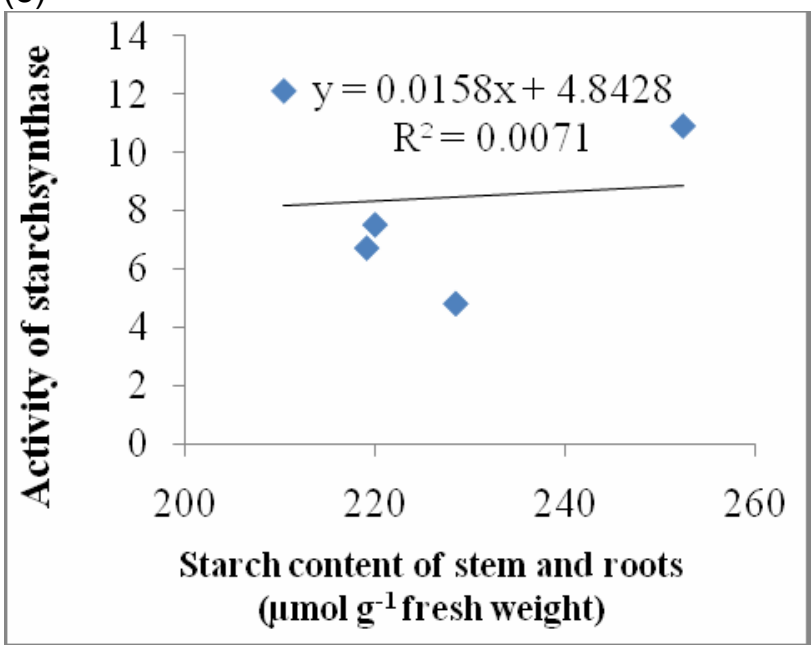

(b)
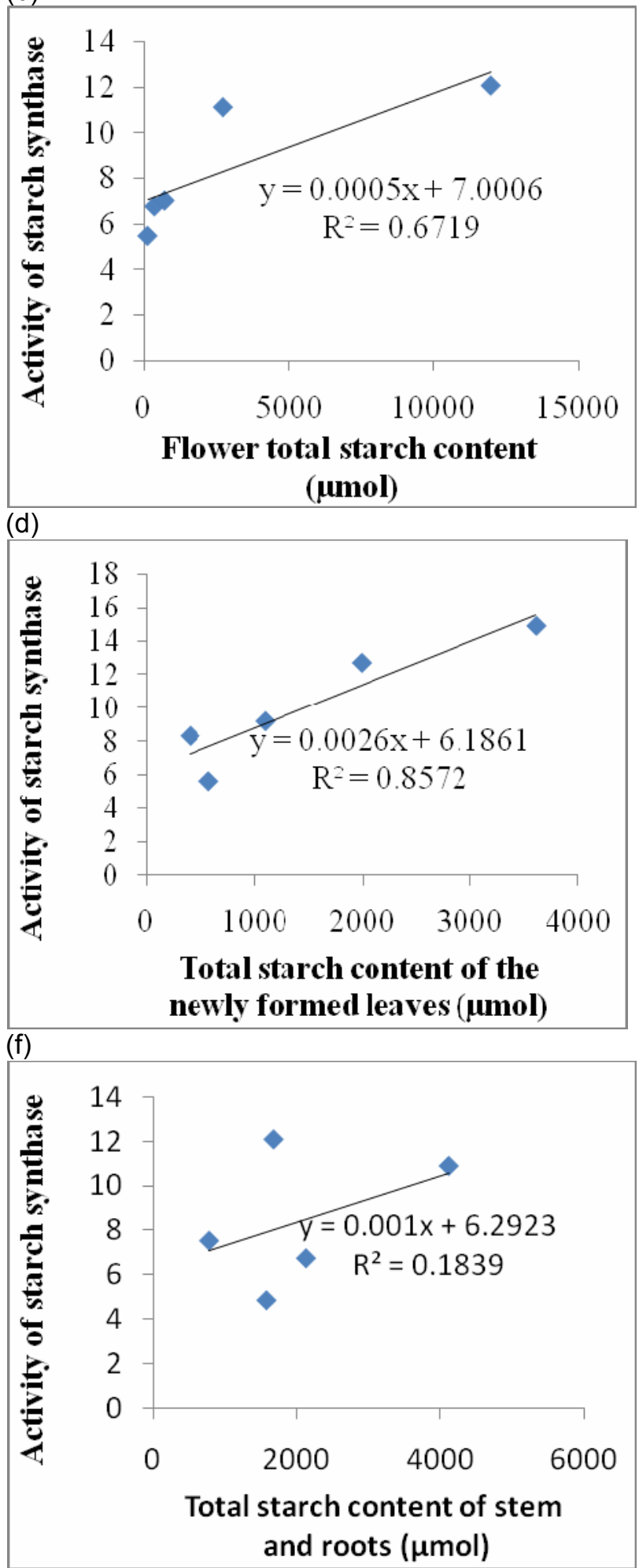

Fig 9: Relationship between the activity of starch synthase (expressed as $\mathrm{nmol} \mathrm{min}^{-1} \mathrm{~g}^{-1}$ fresh weight), and starch accumulation of the newly formed organs of hyacinth. The figure shows that starch accumulation in these organs is proportional to the enzyme activity. 
Agric. Biol. J. N. Am., 2011, 2(2): 279-297

\section{DISCUSSION}

Carbohydrate partitioning and metabolism of hyacinth scale: The general reduction in starch and biomass of the scales of hyacinth after planting of the bulbs is attributed to the occurrence of preformed shoots and roots. These newly developed structures made use of the energy stored in the bulbs for emergence and this is in accordance with the observation made by Theron and Jacobs (1996). According to these authors, reduction in reserve carbohydrate occurs in geophytes during the time of sprouting. This means that in flower bulbs, sprouting is connected with the breakdown of material accumulated in the storage tissues, and the utilisation of these materials is essential for the initial growth (Miller, 1992) and the development of the newly formed organs. In this study, changes in biomass of the bulb scales closely followed that of starch and this was confirmed by the high correlation between the two parameters $(r=0.694$, Table 1). The outer scales recorded higher levels of starch and biomass than the inner scales prior to planting, but the rate of degradation of these parameters was higher of the former than that of the latter particularly during the first month after planting. This is not uncommon in ornamental geophytes as Chen (1969) also made a similar observation in Narcissus tazetta. Du Toit et al. (2004) reported that in Lachenalia, the total dry weight of the bulb and starch content decreased by 80 and $90 \%$, respectively, during sprouting of the bulb in tulips, Lambrechts et al. (1994) also observed that the dry weight of the mother bulb scales decreased to half of the original value at the time of sprouting. In the present study, the period of rapid reduction in starch coincided with the time of sprouting of the bulbs. This means that the degradation of starch of the hyacinth scales fuelled the emergence and growth of the newly formed plant especially at the early stages of growth when no photosynthetically active leaves had been formed. This is in accordance with the finding of Orthen (2001) that in geophytic plants, starch serves as the source of energy during the time of sprouting. The starch content of hyacinth varied from organs to organ, and values measured depended on the stage of growth of the flower bulb. Miller (1992) as well as Miller and Langhans (1989) also made a similar observation. The high values of starch compared with the generally low values of the soluble sugars of the hyacinth scales and the gradual reduction and disappearance of sugars from 4 to 7 months after planting as well as the accumulation of starch in the scales from 5 to 7 month after planting imply that starch was the major storage carbohydrate in hyacinth. Vishnevetsky et al. (2000) also worked on Nerine sarniensis cv Salmon and reported that starch was the dominant storage carbohydrate in that bulb.

Starch metabolism of the various organs of hyacinth: The reduction in starch and biomass of the scales of hyacinth was accompanied by an increase in these parameters of the new leaves, stem and roots and flower (Experiment 2). The accumulation in biomass and starch of these bulbs also reflected in the general growth of these newly developed organs. This is consistent with the observation made by Theron and Jacobs (1996) that reserves stored in bulbs are used for the development of newly formed organs and once the leaves mature to become the photosynthate source, resources may be stored in the old and new leaf bases. Wassink (1965) also stated that in bulbous plants, the aerial parts develop mainly at the expense of the mother bulb. The depletion of scales in biomass and starch and the concomitant accumulation of these resources in the newly developed organs especially during the early stages of growth before photosynthetic leaves were developed also means that the resources were being exported from the scales into these newly formed organs. The flower accumulated the highest amount of biomass and starch following the degradation of the stored reserves in the scales. In bulbous plants, therefore, one cannot rule out the importance of this export of materials or nutrients (reserve carbohydrates) from the scales to the newly formed organs. The greatest contribution of this export of reserves is from the outer scales since its rate of carbohydrate degradation was faster than that of the inner scales.

Distribution of starch metabolising enzymes in hyacinth: Measurements of the enzyme activities of the bulb scales of hyacinth indicated that, the distribution of the enzymes involved in starch metabolism of hyacinth mimicked the distribution pattern exhibited by starch degradation in the scales. That is, the activities of $\alpha$-amylase and starch phosphorylase were higher in the outer scales than the inner scales, indicating that starch degradation was higher in the former than the latter. Similarly, the relationship between the starch content of the outer scales and $\alpha$-amylase activity (Fig 6) was high $\left(r^{2}=\right.$ 0.6331 or $r^{2}=0.7576$ ), whilst the correlation was low $\left(r^{2}=0.3655\right.$ or $\left.r^{2}=0.4077\right)$ for the enzyme activity and starch content of the inner scales. The activity of 
a-amylase increased from planting (September) to two months after planting (November) whilst that of starch phosphorylase increased from planting to 1 month after planting (October). This implies that, in general, at 1-2 months after planting, the activities of a-amylase and starch phosphorylase were high, and this coincides with the period at which sprouting of the bulb occurred. It means therefore that, sprouting in flower bulbs marks the period at which starch degradation is at its peak, and also, the activity of enzymes responsible for starch degradation is high during this time. This observation is thus in support of the finding made by Akazawa and Hara-Nishimura (1985). According to these authors, the activity of starch degrading enzymes as well as starch degradation increases at the time of sprouting in most geophytes. The correlation coefficient between the starch content of the scales, particularly the outer scales and $\alpha$-amylase activity was higher than that between starch phosphorylase and starch content of the scales. This shows that $\alpha$-amylase predicted starch degradation in hyacinth more than did starch phosphorylase. In other words, starch degradation in the common hyacinth occurred through amylolysis rather than phosphorolysis. In general, the activities of these two enzymes decreased 3 months after planting, because at this point, starch degradation was low. The increase in the activities of ADP glucose pyrophosphorylase and starch synthase of the newly formed organs particularly the flower at 1-4 months after planting indicates the accumulation of starch in these organs, and this followed the pattern of starch content in the organs. The activities of the two starch synthesizing enzymes correlated better with starch accumulation of the flower and the newly formed leaves than that of the stem and roots, however, the activities of the two enzymes were similar, implying that ADP glucose pyrophosphorylase and starch synthase were equally responsible for the accumulation of starch in the flower as well as the newly formed leaves but they were less responsible for starch accumulation in the roots and stem. Thomas et al. (1971) also reported that in plants starch synthesis is regulated by ADP glucose pyrophosphorylase and starch synthase and starch branching enzyme. In this study, however, the activity of starch branching enzyme was not measured.

\section{CONCLUSION:}

The bulb scales of hyacinth contain a number of reserved carbohydrates such as starch, glucose, fructose and sucrose but starch is the major storage carbohydrate in this flower bulb. The starch and biomass content of the outer scales especially prior to planting far exceeded those of the inner scales but the rate of degradation of these parameters was higher of the former than that of the latter. In general, the period of rapid reduction in starch coincided with the time of sprouting of the bulbs. Starch degradation occurred through amylolysis rather than phosphorolysis. The reduction in reserved carbohydrates of the bulb scales led to the accumulation of these substances in the newly formed organs. The flower accumulated the highest amount of these reserves whilst the stem and roots accumulated the least amount of these quantities. The distribution pattern depicted by enzymes involved in starch degradation in the bulb scales closely followed that of starch degradation in these organs. Also, starch and biomass accumulation of the newly formed organs mimicked the distribution of the starch synthesizing enzymes in those organs. ADP glucose pyrophosphorylase and starch synthase were equally responsible for the accumulation of starch in the flower as well as the newly formed leaves, however, these enzymes were less responsible for starch accumulation in the stem and roots.

\section{REFERENCES}

Adams, C. A., Broman, T. H., Norby, S. W. and Rinne, R. W. (1981). Occurence of multiple forms of a-amylase and absence of starch phosphorylase in Soya bean seeds. Ann. Bot. 48, 895-903.

Akazawa, T. and Hara-Nishimura, I. (1985). Topographical aspects of biosynthesis, extracellular secretion and intracellular storage of proteins in plant cells. Annu. Rev. Plant. Physiol. 36: 441-472.

Beck, E. and Ziegler, P. (1989). Biosynthesis and degradation of starch in higher plants. Annu Rev Plant Physiol Plant Mol. Biol. 40: 95- 117.

Chen, S. (1969). Carbohydrate metabolism in the narcissus leaf. J. Exp. Bot. 30, 721-725.

Davies, H. V. (1990). Carbohydrate metabolism during sprouting. Am potato J, 67: 815-827.

Dorion S., Lalonde, S. and Saini, H. (1996). Induction of male sterility in wheat by meiotic-stage water deficit is preceded by a decline in invertase activity and changes in carbohydrate metabolism in anthers. Plant Physiol 17: 215-221.

Du Toit, E. S., Robbertse, P. J. and Niederwieser, J. G. (2004). Plant carbohydrate partitioning of Lachenalia CV. Ronina during bulb production. Scentia Hort 102: 433-440. 
Genders, R. (1994). Scented Flora of the World. Robert Hale. London. ISBN 0-7090-5440-8.

Lambrechts, H., Fred Rook and Chris Koloffel. (1994). Carbohydrate Status of Tulip Bulbs during ColdInduced Flower Stalk Elongation and Flowering. Plant Physiol. 104: 515 - 520.

Locy, R. (1998). Plant Biology Laboratory Manual on Starch Phosphorylase, Copyright 1998.

Miller, W.B. and Niu, S. (1990). Invertase of Lilium longiflorum flower buds. Hort Sci 25: 1076.

Miller, W. B. and Langhans, R.W. (1989). Carbohydrate changes in Easter lilies during growth in normal and reduced irradiance environments. J. Amer. Soc. Hort. Sci. 114:310-315.

Miller, W. B. 1992. A review of carbohydrate metabolism in geophytes. Acta Hortic 325:239-246.

Morrell, S. and Rees, A. R. (1986). Control of hexose content of potato tubers. Phytochemistry 25: $1073-$ 1076.

Nakamura, Y., Yuki, K., Park, S-Y. and Ohya, T. (1989). Carbohydrate metabolism in the developing endosperm of rice grains. Plant Cell Physiol 30: 833839.

Oluoha, U., and Ugochukwu, E. N. (1991). Isolation and Kinetic Properties of Phosphorylase from Yellow Yam Tuber (Dioscorea cayenensis). Biol Plantarum (Praha). 33 (4) 246-261.

Orthen, B. (2001). Sprouting of the fructan- and starchstoring geophyte Lachenalia minima: efforts on carbohydrate and water content within the bulbs. Physiol. Plant. 113, 308-314.

Pelleschi, S. Rocher, J-P. and Prioul, J-L. (1997). Effect of water restriction on carbohydrate metabolism and photosynthesis in mature maize leaves. Plant Cell Environ 20: 493-503.

Rees, A. R. (1972). The growth of Bulbs. Applied Aspects of the physiology of ornamental bulbous crop plants. Academic Press Inc. (London) Ltd.
Rochat, C., Wuilleme S, Boutin J-P. and Hedley, C. L. (1995). A mutation at the $r b$ gene, lowering the ADPGPPase activity, affects storage product metabolism of pea seed coats. J Exp Biol 46: 415-421.

Scott, P. (1992). The metabolism of sucrose and maltose by barley microspores. PhD Thesis. Biology, Gonville and Caius College, Cambridge.

Seal, C. E. (2003). Growth, Yield and Grain Carbohydrate Metabolism of Rice (Oryza sativa L.) under Sodium Chloride Salt Stress. PhD Thesis, Biology, University of Sussex.

Smith, C.J. (1999). Carbohydrate biochemistry. In: Lea, P. J., Leegood, R. C. (Eds), Plant Biochemistry and Molecular Biology, $2^{\text {nd }}$ ed. Wiley, Chichester.

Stanley, D., Farnden, K. F. and Macrae, E. A. (2005). Plant $\alpha$-amylases: functions and roles in carbohydrate metabolism. Biologia, Bratislava, 60/Supl. 16: 65-71.

Theron, K. I. and Jacobs, G. (1996). Changes in carbohydrate composition of the different bulb components of Nerine bowdenii W. Watson (Amaryllidaceae). J Am Soc Hortic Sci 121: 343346.

Thomas, J. A., Spradlin, J. E. and Dygert, S. (1971). Plant and animal amylases. In: Boyer PD (ed) The enzymes, 3 edn., vol 5. Academic Press, New York, pp 115-189.

Usher. G. A. 1974. Medicinal uses of plants. Dictionary of Plants Used by Man. Constable ISBN 0094579202.

VBN, Statistiekboek. (2002). Vereniging van Bloemenveilingen in Nederland 2003.

Vishnevetsky, J., Eli Zamski and Meira Ziv. (2000). Carbohydrate metabolism in Nerine sarniensis bulbs developing in liquid culture. Physiologia Plantarum 108: $361-369$.

Wassink, E.C. (1965). Light intensity effects in growth and development of tulips in comparison with those in gladiolus. Meded. LandbHoogesch. Wageningen 65 (15), 1-21.

Zeeman, S. C., Smith, S. M. and Smith, A. M. (2004). The breakdown of starch in leaves. New Phytol. 163: 247261. 